FINDING THE LINE OF BEST FIT: CONSTRUCTING A PROFILE FOR RURAL-BASED INTERNATIONAL MEDICAL GRADUATES IN CANADA

by

Hannah Kovacs, BA Honours, Mount Allison University, 2013

\author{
A Major Research Paper \\ presented to Ryerson University \\ in partial fulfillment of the requirements for the degree of \\ Master of Arts \\ in the Program of \\ Immigration and Settlement Studies
}

Toronto, Ontario, Canada, 2014

(C) Hannah Kovacs 2014 


\section{AUTHOR'S DECLARATION FOR ELECTRONIC SUBMISSION OF A MAJOR RESEARCH PAPER (MRP)}

I hereby declare that I am the sole author of this Major Research Paper. This is a true copy of the MRP, including any required final revisions, as accepted by my examiners.

I authorize Ryerson University to lend this MRP to other institutions or individuals for the purpose of scholarly research

I further authorize Ryerson University to reproduce this MRP by photocopying or by other means, in total or in part, at the request of other institutions or individuals for the purpose of scholarly research.

I understand that my thesis may be made electronically available to the public.

Hannah Kovacs 


\title{
FINDING THE LINE OF BEST FIT: CONSTRUCTING A PROFILE FOR RURAL-BASED INTERNATIONAL MEDICAL GRADUATES IN CANADA
}

\author{
Hannah Kovacs \\ Master of Arts, 2014 \\ Immigration and Settlement Studies \\ Ryerson University
}

\begin{abstract}
Canada's vast landscape has produced challenges in providing equitable access to healthcare for those living in rural and remote areas. Over several decades physician shortages have increasingly compromised rural communities' access to medical services. In response, provinces and territories have recruited international medical graduates (IMGs) to address these shortages. Synthesizing literature and frameworks from American, Australian and Canadian sources, this paper will explore issues related to IMG recruitment and retention to rural practice. Using an evidence-based review of the literature and data from the Canadian Residency Matching Service (CaRMS) this investigation will examine the profiles of IMGs who voluntarily pursue rural practice in hopes of identifying trends and future directions for recruitment and retention efforts.
\end{abstract}

\section{Key words:}

International medical graduates; rural healthcare; underserved populations; retention 


\section{ACKNOWLEDGEMENTS}

I would like to thank the Canadian Residency Matching Service (CaRMS) for permission to access and disseminate data from their Match Report records.

Thank you to a number of individuals at the College of Physicians and Surgeons Ontario and the Royal College of Physicians and Surgeons Canada for their valuable insight.

Finally, thank you to my supervisor Dr. Harald Bauder for his guidance and encouragement, having been there from the very beginning. 


\section{DEDICATION}

For my grandparents, Dr. Laszlo Kovacs and Dr. Edith Kovacs, who immigrated as physicians and retrained in Canada, building a wonderful life for themselves, their children and grandchildren.

Last but not least, for you, Dad. 


\section{TABLE OF CONTENTS}

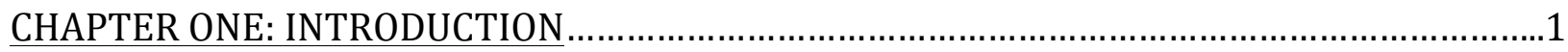

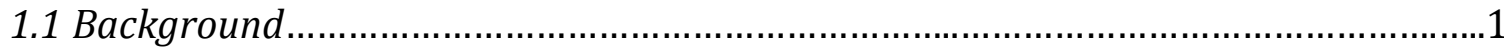

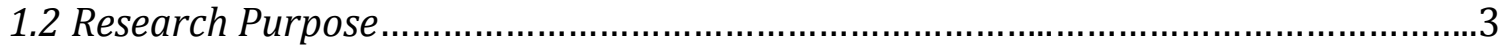

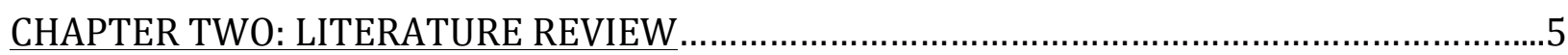

2.1 Contextualizing International Medical Graduates...............................................

2.2 Theoretical Framework.................................................................................11

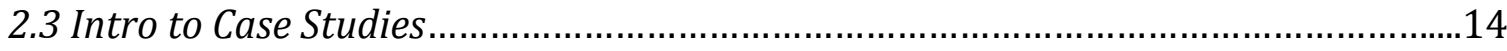

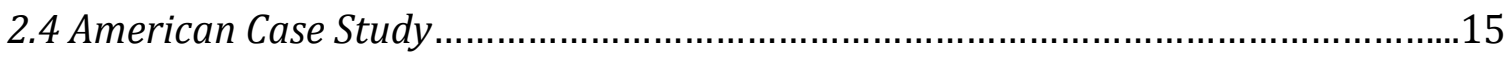

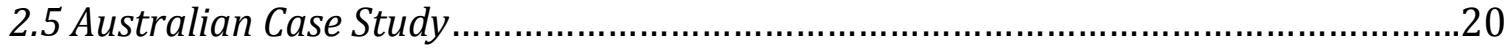

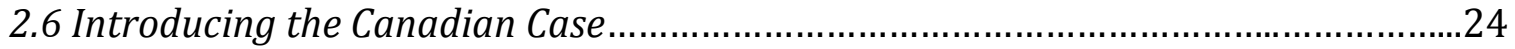

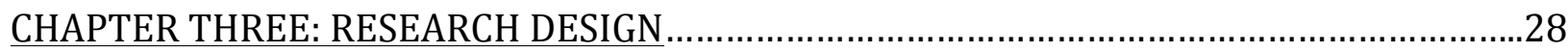

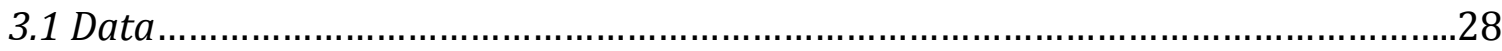

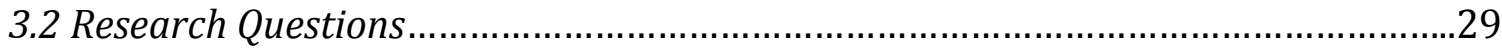

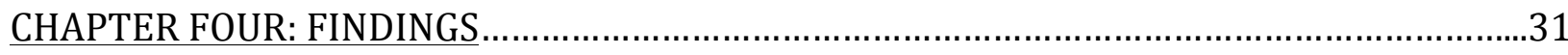

4.1 IMG Participation and Match Rates.....................................................................31

4.2 IMG Discipline Choice and Preference ...............................................................32

4.3 Residency Training Locations and Distribution ......................................................34

4.4 IMG Source Countries and Regional Distribution ...................................................37

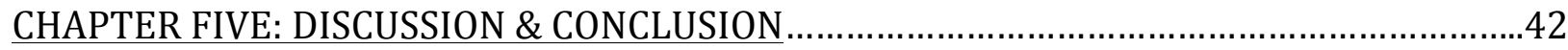

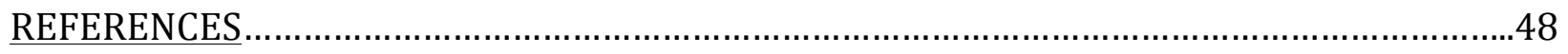




\section{LIST OF TABLES \& FIGURES}

\section{TABLES}

Table 1. Physician Licensure Requirements Ontario.............................................8

Table 2. International Medical Schools with Greatest Number of Graduates

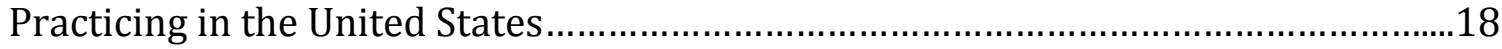

Table 3. Percentage and Number of Matched IMGs............................................31

Table 4. IMG Applicants to Family Medicine, Internal Medicine and Pediatrics........32

Table 5. Family Medicine as First Choice Discipline for IMGS and CMGS..................34

Table 6. Universities with designated Rural Family Medicine Programs..................35

Table 7. IMGs Matched to Family Medicine in First Iteration...................................35

\section{FIGURES}

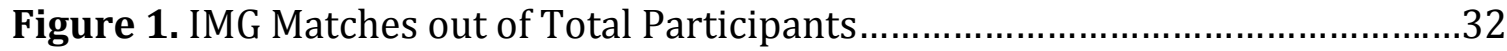

Figure 2. IMG Participation from Central America/Caribbean................................38

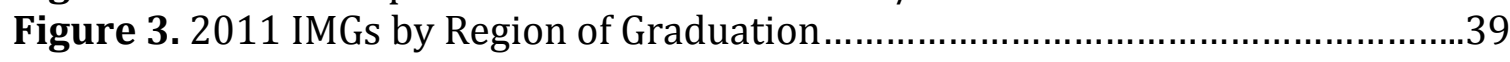

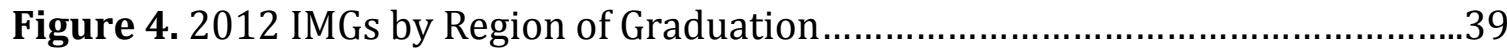

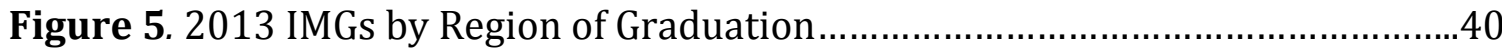

Figure 6. 2014 IMGs by Region of Graduation ................................................. 


\section{CHAPTER ONE: INTRODUCTION}

\subsection{Background}

Nineteen percent of Canadians live in rural settings, geography that accounts for over 95\% of Canada's vast landmass (Statistics Canada, 2011). Remarkably, most Canadians living in these remote settings have reasonable access to the necessities of daily living. Access to healthcare and specifically access to physicians is, however, an ongoing challenge. According to the Canadian Institute for Health Information (2012), Canada boasts 214 physicians per 100,000, yet only $8.5 \%$ of Canada's physician work force serves the 6.3 million residing in rural areas. These statistics are concerning and threaten a basic right of Canadians to have universal access to health care. How is Canada addressing this growing gap between urban and rural access to physicians?

In 2012, the Canadian Medical Association (CMA) recorded 72,368 registered physicians in Canada, 17,407 (24.1\%) of whom received their medical degree outside of the country (Association of Faculties of Medicine of Canada, 2012). Between 2005 and 2010, 13,440 international medical graduates (IMGs) passed the Medical Council of Canada Evaluating Exam (Association of Faculties of Medicine of Canada, 2012). A large portion of Canada's physicians and 'physicians-in-waiting' are internationally trained and are recognized as an important source for addressing healthcare service gaps in rural areas. The term "IMG" will be used in reference to immigrants living in Canada who have completed a MD degree outside of the country.

A disproportionate number of internationally trained physicians working in Canada practice in predominantly rural areas (Saskatchewan, 54.8\% and Newfoundland, 41.7\%) (Dove, 2009; Canadian Institute for Health Information, 2009). These same areas however 
struggle in attracting and retaining physicians, IMGs and domestic grads, beyond their contractual obligations. Contractual obligations most often accompany provisional licenses, where internationally trained physicians practice with restrictions and under supervision over a defined period of time. Until they have fulfilled the requirements for full licensure, it is common for these individuals to be placed in underserved areas as a means of addressing regional physician shortages (Viscomi et al., 2012). Evidence suggests that upon completion of their contracts in rural areas IMGs are likely to migrate back to urban centers, resulting in high turnover rates and compromised continuity of care in rural settings (Wilson, 2011; Viscomi et al., 2012). In Canada, close to 90\% of IMGs who completed their rural placements subsequently migrated to urban centers (mostly in Ontario) due in part to generous financial compensation and proximity to their ethnic identity (Dove, 2009).

These observations made by Dove are further supported in research conducted by Di Biase and Bauder (2005) who found that immigrants arriving to Canada could not envision settling in remote, rural communities due to their perception of such regions as "unknown." The authors observed that newcomers have a tendency to assume that employment opportunities in rural areas will not match their occupational skills and are weary of the lack of immigrant and settlement services available to help ease their transition into the Canadian life. More recent research by Margaret Walton-Roberts (2012) suggests that this mentality is exacerbated by the lack of involvement by municipal governments in addressing the unique needs of rural community members. It is entirely possible that IMGs would encounter similar issues in rural contexts. Generally speaking, physician retention in rural areas can be difficult due to the heavy workload, the 
requirement of a diverse skillset, professional isolation, urban lifestyle preference and lack of career options (Geyman et al., 2000). Similarly, an Australian study found that internationally trained physicians and IMGs were more likely to remain in rural areas if there was a supportive community environment, the potential to maintain cultural and religious ties, opportunities for spouses and children and professional support mechanisms (Han \& Humphreys, 2005).

\subsection{Research Purpose}

Given Canada's rural physician shortage and poor regional distribution of health professionals, it is important to examine how Canada plans to address the long-term sustainability of healthcare delivery in rural settings. International medical graduates have proven to be central to the delivery of this care. With a dwindling supply of domestic medical graduates and physicians willing to practice in rural areas, how will Canada ensure reasonable access to health care in underserved areas? This paper will explore what motivates IMGs to stay and leave rural practice. It is critical to understand the characteristics and background of IMGs to help provide deeper insight into issues related to rural physician retention and the resultant access to healthcare.

Using data sources from the Canadian Residency Matching Service (CaRMS) I will analyze the IMG demographic in Canada, examining how this population is distributed across disciplines, training locations and regions. This inquiry will examine rural IMG recruitment in Canada, exploring how IMGs have contributed and continue to contribute to the delivery of healthcare in underserved areas. Through my review and analysis of the literature and strategies in Canada and other countries it is my hope that my work will 
offer constructive evidence-based input on how Canadian health authorities, academic institutions and government bodies can improve IMG retention in rural Canadian settings. 
CHAPTER TWO: LITERATURE REVIEW

\subsection{Contextualizing International Medical Graduates}

One of the most common misconceptions concerning physician shortages, wherever they may exist, pertains to the perceived undersupply of medical graduates. Let us first consider the medical graduate demographic in the United States. The AAMC Center for Workforce Studies has projected that by 2025 the United States will be faced with a shortage of full-time physicians calculated to be 124,000 (Dill \& Salsberg, 2008). Unfortunately, boosting enrollment and opening new schools would not solve this issue. Physicians, whether domestically or internationally trained, are unable to practice unless they have completed their postgraduate residency training. In 2013, a total of 34,314 applications were submitted for residency positions sanctioned by the Accreditation Council for Graduate Medical Education for 26,000 available positions (Grover, 2013). Of the 34,314 applicants, 7,568 were foreign-born and internationally trained, accounting for the second largest proportion of medical graduates next to domestic (US) medical graduates $(17,487)$; other competing groups include US-born IMGs $(5,095)$ and US Doctors of Osteopathic Medicine $(2,677)$ (Grover, 2013). Consequently, IMGs had the lowest match ratio, that is, the number of medical graduate applicants to the number of graduates matched to a residency position. Three thousand nine hundred and sixty seven (52.4\%) IMGs were left unmatched to a residency position, while only 1,097 (6.3\%) of the 17,487 US medical graduates were unable to secure residency (Grover, 2013).

The limited number of residency positions is directly related to the amount of government funding available. In the United States graduate medical education funding was cut drastically in 1997 in an effort to minimize the deficit through a spending freeze 
(Dill \& Salsberg, 2008). Residency positions have remained tightly capped, limiting the number of physicians who can enter practice. This has created a bottleneck effect where American schools have successfully increased the number of medical graduates through higher enrollment rates, yet residency applicants continue to outnumber training positions available. This is a reality that many countries are facing in the wake of physician shortages and emphasizes the need to address the issue with a critical lens.

As previously discussed, IMGs account for a significant portion of many countries' medical graduate pool, a documented trend in the United States, Australia and Canada (Arah et al., 2008). The movement and spatial distribution of these internationally trained physicians is of particular interest in that a large majority of IMGs are used to supply underserved regions in rural environments, a paradigm that strongly resonates across Canada's rural landscape (Dauphinee, 2005).

Before examining the individual experiences of IMGs in the United States, Australia and Canada, it is necessary to understand the migration of IMGs in a theoretical framework. To do this, it is important to look at the conditions that have enabled trained professionals, such as IMGs, to cross borders in pursuit of employment or training. First and foremost, is the internationalization of higher education, especially in industrialized countries such as the US, UK, Australia and Canada, which has attracted a large number of migrants seeking educational and employment opportunities beyond the borders of their country of origin (Iredale, 2002). Increased collaboration between institutions in both developing countries and developed countries has allowed individuals to study and invest in 'western' education, often perceived as a guaranteed ticket to secure meaningful employment (Altbach \& Knight, 2007). 
For IMGs, acquiring full licensure in a host country almost always requires some retraining at local institutions as designated by governing regulatory bodies. The degree of retraining required depends on the relationship between institutions in both the country of origin and receiving country. For example, among Commonwealth countries medical education and training reciprocity has been established to facilitate the movement of professionals between member countries, including the United Kingdom, Ireland, Canada, South Africa, Australia, New Zealand, India, Sri Lanka, Hong Kong and Singapore (Iredale, 2002). However, the medical profession's transnational profile does not unanimously ensure accreditation transfer equity. Health workers' mobility has long been tightly regulated by government frameworks that control "the training, recruitment and deployment of health professionals, which gives rise to particular national patterns of migration" (Bach, 2008, p. 204). As observed by Iredale, "the medical profession in most countries is characterized by a history of barriers erected to exclude foreign practitioners" (2002, p. 12). Consequently, the exclusion of internationally trained physicians narrows the pool of potential practitioners in terms of the diversity in training background, context and experience. Thus, labour market shortages have emerged as a result of a disinterest in rural practice, placing enormous strains on remote communities in the United States, United Kingdom, Canada, Australia, New Zealand and South Africa (Scheffler et al., 2008).

Consider Canada's case: significant barriers to licensure for IMGs continue to exist, despite regulatory bodies and health authorities having recognized the need to recruit such physicians to address physician labour shortages in underserved regions (Buske, 2008). The road to licensure is a long one, beginning with the Medical Council of Canada (MCC), which oversees undergraduate medicine. The Medical Council of Canada is responsible for 
evaluating new Canadian medical graduates and those foreign-trained physicians who have successfully completed approved programs abroad in a two-part examination. Upon successful completion of the examinations, practitioners are granted the Licentiate of the Medical Council of Canada (LMCC), a prerequisite for obtaining a practice license in the province or territory where he or she resides. The provincial/territorial regulatory bodies individually control the distribution of licenses to practice medicine based on set requirements. In Ontario, the College of Physicians and Surgeons requires physicians seeking full licensure to meet the following requirements listed below in Table 1 . Navigating such a complex licensing system has been identified as significantly problematic for IMGs due to language barriers, examination and retraining costs, and lengthy time commitments (Boyd \& Schellenberg, 2007).

\begin{tabular}{|l|}
\hline Canadian citizenship/landed immigrant status \\
\hline Completion of MCCQE Parts 1 and $2^{1}$ \\
\hline Certification from national regulatory body ${ }^{2}$ \\
\hline Completion of residency training in Canada \\
\hline
\end{tabular}

Table 1. Physician licensure requirements for physicians in Ontario

Once physicians have met the licensing requirements and secured a residency, it is common for practitioners to enter return of service agreements, requiring physicians who receive subsidized postgraduate residency medical training to practice in a specific community as designated by the agreement. Return of service agreements often place soon-to-be licensed physicians in rural communities; failure to fulfill the service agreement results in an incomplete application and leaves the physician without full licensure.

\footnotetext{
${ }^{1}$ Medical Council of Canada Qualifying Examinations (MCCQE) Part 1 and Part 2

${ }^{2}$ Certification required from either the Royal College of Physicians and Surgeons of Canada or the College of Family Physicians of Canada
} 
Saskatchewan, for example, provides grants, subsidies and loans to individuals who wish to further their health service training, under the terms of a return of service agreement (Saskatchewan Chamber of Commerce, 2011). Fulfillment of the contractual agreement results in full licensure provided that the individual becomes "licensed by the College of Physicians and Surgeons of Saskatchewan and [begins] the practice of medicine, in the specialty area that the funding was provided, in a community in Saskatchewan" (Family Medicine R3 Emergency Resident Medical Training Agreement, 2011, p. 2). The agreement specifies that the contract holder must work on a full-time basis, for one year in an area as designated by the service agreement - rural or urban - before receiving full licensure from the College (Family Medicine R3 Emergency Resident Medical Training Agreement, 2011). It is important to note that return of service agreements do differ from province to province. In Ontario, return of service agreements for medical residents require a 5 year commitment (Wenghofer et al., 2011) and 3 years in Newfoundland (Greenaway, 2011). Like Canada, Australia utilizes a 'condition of service' program, which restricts IMGs to practice in areas designated as underserved for up to 10 years, most often in rural communities. Under the Health Insurance Act, Australian health authorities have sought to rebalance physician distribution, addressing the excess number of general practitioners (GPs) in urban centers (McGrath et al., 2012). Because Australia has been unable to attract sufficient numbers of domestic medical graduates to satisfy the undersupply of health professionals in the country's rural regions, the condition of service program has increased the number of IMGs in rural practice. These IMGs account for $41 \%$ of all physicians in rural Australia (McGrath et al., 2012). By recruiting highly skilled professionals, such as physicians, health authorities intend to capitalize on the skills and abilities of 
internationally trained physicians. However, there are concerns in what seems to be a fine line between capitalizing and exploiting when IMGs are involuntarily placed in communities that may not accommodate their lifestyle preferences and/or training background. This argument has been explored by W. Dale Dauphinee (2005), who found that both Canadian Medical Graduates and IMGs have opted to migrate to the United States in pursuit of a more diverse pool of employment opportunities with more positions in a variety of locations and work environments. Moreover, Dauphinee (2005) observed that, "Migration to and from the United States is a key factor in physician workforce stability in Canada," (p. 24) pointing to a need for stakeholders to be mindful of how policy serves to anchor physicians, sometimes involuntarily, in undesirable work environments.

In the United States, IMGs participate in post-graduate training via the J-1 visa waiver program, requiring that participants return to their country of origin for a minimum of two years upon completion of their training (Boulet et al., 2006). Consequently, J-1 visas allow IMGs to remain in the US if they work in a Health Professional Shortage Area for a minimum of three years (Boulet et al., 2006). What do all of these programs have in common? Research has shown that service agreements have failed to retain IMGs beyond the respective timeframes as designated by the individual programs (Audas et al., 2008; McGrath et al., 2011; Boulet et al, 2006). Furthermore, the policies on which these programs are based have not been cognizant of IMGs' settlement and practice preferences, thereby IMGs' autonomy and freedom of choice. 


\subsection{Theoretical Framework}

Richard Florida's creative class theory provides a fitting theoretical framework to help understand the conditions that make metropolitan areas a more attractive environment for settlement, especially in the case of highly trained professionals. Florida (2006) suggests that the new, emerging economic climate is fueled by creativity and diversity. The post-industrial era has produced conditions where employment, wealth and income are generated by talented, skilled professionals. These populations are organized into "regional clusters" that compete with one another to attract the world's most talented and brightest individuals. Florida (2006) views these environments as ones that are dominated by the "3T's" - technology, talent and tolerance, all of which contribute to successful economic development. Within these concentrations, individuals interact with an inclusive culture that is tolerant of diverse ways of thinking, new ideas and innovative technologies that come together and facilitate the creation and production of ideas (Florida, 2006).

While the rise of the creative class is promising and exciting in the context of global economic development, Florida's metropolitan-centric theory tends to cast a second class shadow over rural areas. In one of his more recent publications, Florida acknowledges that many have expressed curiosity in how rural areas factor into the theory and whether they are being left behind in the midst of our climb to an all-encompassing Creative Age. He writes, "The short answer is that their fortunes are divided: some are prospering; others are falling further behind" (Florida, 2012, p.333). He references a study conducted by the US Department of Agriculture that measured and compared creative classes across 3,000 US counties, both rural and metropolitan. Interestingly, the Creative Class accounted for 
$20 \%$ of employment in rural areas and 31\% among metropolitan areas (Florida, 2012). The authors of the study observed that the rural Creative Class exhibited lower levels of higher education, with denser concentrations of the rural Creative Class surrounding leading rural universities and institutions (Florida, 2012). "Remaking our fading suburbs and rural areas might well turn out to be the biggest urban revitalization challenge of modern times - far larger in scale, scope and cost than the revitalization of our inner cities," (Florida, 2012, p. 334) a reflection that would perhaps resonate with health authorities struggling to attract and retain rural-based physicians.

Research by Margaret Walton-Roberts has strongly emphasized the importance of boosting immigrant populations to 'second tier cities'. Second tier cities (STCs), described by Walton-Roberts (2011) as, "rapidly growing, newly emerging medium-sized industrial cities that challenge established urban hierarchies" (p. 1) can include rural communities. STCs are not necessarily defined by population size, but rather by the distinct economic activities that trigger employment and population growth, recognition of universities and colleges, provide sources of employment and promote innovation and economic prosperity (Walton-Roberts, 2011; Haggblade, 2010). Walton-Roberts' (2011) research found “the role of the university as an important factor influencing settlement experiences" (p. 11) due to such institutions being the locus of ethnic minority diversity in a community that might otherwise be void of an immigrant presence. The study by the US Department of Agriculture study cited by Florida (2012) finding denser concentrations of the rural Creative Class surrounding universities and other higher-learning institutions offers evidence to suggest that universities located in remote areas - or STCs - not only serve to boost the knowledge-based, 'nonfarm' economy but also increase the ethnic diversity of 
professionals and the broader Creative Class population. Walton-Roberts (2011) argues, "Universities and colleges have become one of the main routes by which a visible-minority population has come to enter the community" (p. 12). It is possible that internationally trained professionals, such as IMGs, would be more likely to voluntarily settle in rural communities equipped with a higher-learning institution due to the greater number of employment opportunities, population diversity and further educational opportunities.

Florida's Creative Class includes "architects to aesthetic workers, engineers and scientists to artists and writers, high-end managers, planners, and analysts to health care, finance and law professionals" (Florida, 2006, p. 28). It is understandable therefore that IMGs would be more inclined to train and practice in urban environments which offer diversity in terms of language, religion, culture and lifestyles (Florida, 2012). As Florida states, "the more urban the setting, the more diverse and hence more creative such a group is likely to be" (Florida, 2012, p. 202). However this argument alone fails to recognize the appeal of rural areas as attractive environments to live and work. As proven by the US Department of Agriculture study and Walton-Roberts (2011), Creative Class clustering is not exclusively limited to metropolitan areas. Florida (2012) states, "The idea that clustering only happens in Manhattan-style urban centers is shortsighted and parochial," (p. 329) an observation that serves to remind us of the value and potential that lies in rural communities, whether in the United States, Australia or Canada.

In the wake of a growing need to market rural areas as habitable and fruitful environments, the Creative Class theory offers a platform to better understand the unique push-pull factors that influence IMGs' decision to leave rural communities upon completion of their agreements and respective training programs. Florida (2012) makes reference to 
research conducted by Peter J. Rentfrow on the geography of personalities, finding that "there is a psychological dimension to creative cities that contributes to their ethos and character" and furthermore, "It is not just that people sort themselves into places where they can find work...they seek out environments where they can pursue their personal as well as their professional interests" (p. 252). In 'remaking' rural communities, as Florida suggests, it is important to recognize that some of these environments have, albeit to a lesser extent, a creative capacity and value.

In the context of this discussion, the challenge is in managing supply and demand; matching IMGs to positions in locations that offer a reasonable personal lifestyle, training experience and employment opportunities. Without inhibiting IMGs' freedom of choice and mobility, one must consider the possibility of tapping into a distinctive Creative Class pool that has both talent (i.e. relevant experience and training) and tolerance (i.e. that they are satisfied with a rural lifestyle). Supporting literature (Florida, 2012; Haggblade, 2010; Walton-Roberts, 2011) has been synthesized to form an argument that suggests health authorities may benefit from acknowledging the role of universities and associated resources in attracting and retaining rural-based internationally trained physicians.

\subsection{Intro to Case Studies}

Like Canada, the United States and Australia are geographically defined by their vast landscapes. Metropolitan areas of all shapes and sizes are home to a majority of their respective populations. However beyond the bustling metropolises, in the periphery, exist countless rural communities that expect access to the same basic essential services as are available in more urban centers including and, perhaps most importantly, healthcare. 
Research from the United States and Australia has generated considerable insight into the role of IMGs in addressing the shortfall of health professionals in rural areas. Using available literature to date, the following discussion will provide an in-depth understanding of what motivates IMGs to stay or leave from rural practice. Compared to the US and Australia there is relatively little published on the Canadian experience with IMGs in rural regions. The geography, language, culture and healthcare systems of these two countries bear reasonable similarity to those of Canada and will provide a window of observation for my investigation.

International medical graduates are an integral and essential part of the American and Australian rural physician workforce. Some literature (Wilkinson, 2003; Audas et al., 2008; Mathews et al., 2008) suggests that, generally, rural physician retention may be more common among populations of medical graduates who received education and/or training in rural contexts. Each of these case studies will consider this argument from an IMGs' perspective in an effort to understand what particular groups and characteristics are likely to voluntarily pursue practice in rural communities.

\subsection{American Case Study}

Statistics gathered by the World Bank in 2012 measured the rural population in the United States at $54,542,564$, corresponding to $18.6 \%$ of the country's total population (Trading Economics, 2012). No different from their fellow American urbanites, rural populations require access to healthcare facilities and professionals. Family physicians are the major actors in the delivery of rural healthcare, as they receive $42 \%$ of the visits made by rural-based Americans (Ruddy et al., 2005). In the medical domain, such physicians are 
referred to as generalists, implying that they possess a broad and diverse skillset that can be effectively mobilized across rural contexts (Smith \& Hays, 2004; Pong et al., 2005).

Active recruitment of generalist physicians has been particularly strong in the northwest United States. States such as Alaska, Idaho, Montana and Wyoming all have significant rural populations and are therefore dependent on a strategic distribution of healthcare services (Pong et al., 2005). The University of Washington in Seattle, for example, has taken measures to increase the number of generalist practitioners in their respective underserved regions; rural rotations offered by the Family Practice Residency Network in association with the university provide exposure to rural practice at different sites throughout the five states (Pong et al., 2005). Of the 24 graduates who took a rural residency placement in the first year of the program, $83 \%$ went on to practice in rural regions (Pong et al., 2005).

Where then do IMGs fit in? Dialogue around the role of IMGs in temporarily addressing these shortages and, to a lesser extent, the issues surrounding retention of IMGs in underserved regions has gained traction over the last decade. The literature gap persists in relation to the profile of IMGs who stay and practice in rural environments beyond their initial contractual obligations. Closing this gap is crucial as IMGs become a larger part of the national physician workforce, especially in rural regions. It is critical to understand what type of physician is both capable, willing and content to stay in long-term rural practice so as to ensure uncompromised, sustainable healthcare. To date, no such profile exists for IMGs in the United States.

A study conducted by Florida State on the rural physician workforce found that of 272 rural physicians surveyed, $48.8 \%$ were foreign-born, $34.9 \%$ practiced family medicine 
and 26\% had a rural upbringing (Brooks et al., 2003). Comparatively, of the 385 urban physicians surveyed, $39.5 \%$ were foreign-born, $17.9 \%$ practiced family medicine and 13.1\% had a rural upbringing (Brooks et al., 2003). The higher percentage of family physicians in rural areas lends support to the notion of such physicians being generalists, possessing a versatile skillset. It is possible that generalists may be an ideal group to recruit for rural practice; whether IMGs in particular exhibit strong skills in this domain has yet to be determined.

Furthermore, the study found that "during medical school, students who were heavily exposed to rural medical practice or living in a rural community were most likely to go on and practice in a rural area" (Brooks et al., 2003, p. 486). Sixty-one percent of rural physicians surveyed received medical training in rural areas and $87.4 \%$ received training in underserved population medicine, suggesting that medical training and education in a rural context and subject area has strongly influenced physicians' decisions to practice rural medicine.

It is interesting to note that $43.6 \%$ of the rural physician sample had attended a medical school outside of the country, compared to $35.5 \%$ of the urban physician sample (Brooks et al., 2003). In an effort to differentiate between US-born IMGs and foreign-born IMGs, the authors were able to determine that $55.2 \%$ of foreign-born IMGs received medical training in rural areas and $59.7 \%$ received specific training in the domain of rural medicine (Brooks et al., 2003). Although US-born IMGs revealed higher percentages in regard to rural medical training and rural medicine education $(66.3 \%$ and $65.6 \%$, respectively), the findings suggest that a significant portion of foreign-born IMGs in Florida have had ample exposure to rural education and training. 
This data demonstrates that medical education background and exposure are reliable indicators of voluntary rural practice amongst IMGs. As acknowledged by the authors, "the finding that almost half of all rural [primary care physicians] were foreign born has important policy implications, particularly as medical educators look for ways to meet the needs of rural communities" (Brooks et al., 2003, p. 489). There have been few studies that have made a similar acknowledgement, further emphasizing the need to create a national profile for IMGs practicing in rural America and to determine what can be done to ameliorate the rural healthcare experience for both physicians and American citizens.

A more recent survey conducted by Young et al. (2012) provides material that works towards a more current and broader understanding of the national IMG profile. The study reported that as of 2012, there were 196,573 IMGs with active licenses in the United States (Young et al., 2012). The authors tracked where these IMGs completed medical school. Table 2 below displays 10 international medical schools with the greatest number of graduates who are actively practicing in the United States.

\begin{tabular}{|l|l|l|}
\hline $\begin{array}{l}\text { International Medical Schools with the Greatest } \\
\text { Number of Graduates Having an Active License } \\
\text { to Practice Medicine in the United States, 2012 }\end{array}$ & Country & $\begin{array}{l}\text { Number of Actively } \\
\text { Licenses Physicians }\end{array}$ \\
\hline International Medical School & Grenada & 6,518 \\
\hline St. Georges University & Dominica & 5,647 \\
\hline Ross University & Mexico & 5,260 \\
\hline Universidad Autonoma De Guadalajara & Philippines & 5,165 \\
\hline University of Santo Tomas & Satin Maarten & 3,387 \\
\hline American University of the Caribbean & Pakistan & 3,013 \\
\hline Dow University of Health Sciences & Syria & 2,483 \\
\hline University of Damascus & Philippines & 2,207 \\
\hline $\begin{array}{l}\text { University of the East Ramon Magsaysay Medical } \\
\text { Center }\end{array}$ & Philippines & 2,081 \\
\hline University of the Philippines & India & 2,065 \\
\hline Osmania Medical College &
\end{tabular}

Table 2. International Medical Schools with Greatest Number of Graduates

Note. Adapted from A census of actively licensed physicians in the United States, p. 15, Young et al., 2012, Journal of Medical Regulation 
Of the 196,573 IMGs practicing in the United States, $23 \%(45,558)$ graduated from schools in India (Young et al., 2012). As Table 2 indicates Osmania Medical College graduated the largest number of IMGs within India successfully practicing in the United States. The Philippines graduated the second largest percentage of IMGs (8\%), followed by the University of Santo Tomas, University of the East Ramon Magsaysay Medical Center and the University of the Philippines collectively graduating the largest numbers of practicing physicians. Pakistan and Mexico made the third and fourth largest IMG contribution at $6 \%$ and 5\%, respectively. Although the university of St. Georges itself graduated the largest number of IMGs overall, Grenada's total IMG output was noncompetitive with that of India and the Philippines. However also of great importance, Young et al. (2012) observed a significant rise in licensed IMGs from Caribbean medical schools since 2010, increasing to $13 \%$ of the total IMG population by 2012. High output schools such as St. Georges in Grenada may be contributing to the surge of licensed IMGs from the Caribbean region.

The study concluded that as the population of actively licensed physicians continues to grow in the United States, so will the diversity of physicians with respect to medical education and training backgrounds. In reference to the rise in Caribbean graduates there has been a steady increase in medical education programs from this region between 2010 and 2012. "The number of IMGs with an active license who graduated from a medical school in the Caribbean, many of whom are US citizens, grew at a faster pace $(14 \%)$ from 2010 to 2012 than the number of actively licensed physicians who graduated from all international medical schools (4\%)," an observation that may be of interest to health authorities looking for source countries in lieu of increasing shortages (Young et al., 2012, p. 19). 
It is worth noting that the study did not specify what proportion of actively licensed IMGs had received rural medical education and/or training. It may be useful to examine the population of graduates from family medicine streams as "family medicine has demonstrated a sustained emphasis on training students to prepare for service in rural areas through programs such as rural training tracks and post-residency fellowships in rural medicine" (Ruddy et al., 2005 p. 147). Of the top ten international medical schools mentioned by Young et al., it would be interesting to determine the proportion and locations of actively licensed graduates (in the United States) practicing family medicine. It is possible that some international schools - over others - may have a tendency to graduate a significant number of IMGs prepared, trained and willing to practice in rural environments due to the geographical setting or orientation of their medical programs. Identifying this population of IMGs could have important implications for the intensifying physician shortage across many countries, an argument that will be further explored in the Canadian context.

\subsection{Australian Case Study}

Statistics gathered by the World Bank in 2012 estimate the rural population in Australia at $2,420,731$, corresponding to $11.3 \%$ of the country's total population (Trading Economics, 2012). Although proportionately smaller than the United States, Australian rural communities are no less interested in 'remaking' the rural healthcare experience for community members. Comparatively, Australia's recorded urban population is $19,077,769$ (Trading Economics, 2012). In these areas, according to Grobler et al. (2009), there is one physician for every 970 people and in rural regions one for every 1,328 . 
Although most of the published literature pertaining to IMGs and rural retention represents data from the United States, Australian researchers have also made valuable contributions on this same issue. Australia has devoted a significant amount of attention towards the program evaluation of interventions implemented to improve rates of physician retention in rural regions (Grobler et al., 2009; Jones et al., 2001; Laven et al., 2003). Interestingly, in Australia all IMGs are required to spend ten years working in a "district of workforce shortage" as designated by the Rural Workforce Agencies (Frehywot et al., 2010). Drawing from Florida's Creative Class theory, it is possible that such efforts can be attributed to Australia's desire to 'remake' the country's rural areas by attracting and boosting Creative Class participation. Commonly referred to as 'compulsory programmes' or 'return of service agreements', health authorities and regulatory bodies are able to direct the flow of Creative Class settlement - in this case, IMGs - who in return receive full licensure and/or generous financial compensation. In Australia such initiatives carry a price tag upwards of $\$ 10$ million US, sourced primarily from the taxpayer pool for the purpose of offering incentives to physicians considering rural practice (Frehywot et al., 2010).

As previously mentioned, there are concerns where compulsory program participation becomes an involuntary pathway to full licensure and resettlement in a new country. This issue is critical to the dialogue surrounding IMGs and rural retention. The question remains: who are the physicians willing to practice in rural areas and are they capable? Alexander and Fraser (2007) surveyed IMGs in rural practice across Australia and found that $89 \%$ of respondents were satisfied with their current medical practice. However respondents also indicated that the rural environment lacked sufficient support and were 
largely absent of programs administered by accredited professional organizations for the advancement of business practices, clinical skills and consultation skills (Alexander \& Fraser, 2007). Moreover, respondents expressed personal knowledge gaps that included indigenous health and key rural health issues (Alexander \& Fraser, 2007).

It is possible that Alexander and Fraser's sample of IMGs may not have had sufficient background training and education in rural health. One might argue that IMG recruitment efforts via compulsory service programs could be refined to match generalist specialists or family physicians who have experience in rural medicine with positions in underserved regions. As discussed in the American case study, there is compelling evidence to suggest that physicians may be inclined to enter rural practice if they have received medical education and training in rural contexts. Australian researchers seem to agree that "[f]ollowing the establishment of rural clinical schools, the number of medical students selecting rural regional hospitals as their preferred site for internship increased..." (Grobler et al., 2009 p. 12). For IMGs working towards full licensure, it would be productive for stakeholders to actively recruit IMGs with family medicine and/or rural health experience to residency programs in rural contexts. It has been established that residency programs do this for domestic medical graduates; the possible benefits of doing the same for IMGs remains largely unchartered territory, presenting an opportunity of investigation for policy analysts and researchers.

As previously mentioned, it is important to consider the features of rural landscapes that make such a lifestyle either attractive or unattractive to an IMG. Similar to the findings of Alexander and Fraser (2007), Han and Humphreys (2006) observed that systematic, organized professional support mechanisms, educational facilities for children and work 
opportunities for their spouses ranked among the top indicators of retention among IMGs in Australia. Furthermore, Han and Humphreys (2006) concluded that IMGs aware of the 10-year rural service condition prior to emigration were diverse in composition, "characterized by both rural and urban backgrounds, diverse religious, cultural/ethnic backgrounds" (p. 202). This group of physicians was found to serve in rural communities beyond their initial contractual obligations, suggesting that - in this study's given sample no one cultural or ethnic group showed a preference for rural practice and settlement. Thus it is plausible that exposure to rural medicine and training may be the most significant indicator of long-term rural practice retention.

Data from Australian literature has helped inform stakeholders of the necessary support mechanisms required for a sustainable rural healthcare workforce. Alexander and Fraser (2007), Han and Humphreys (2006) and Henry et al. (2009) have consistently observed the need for improved professional support at both the state and national level, viable career pathway opportunities for practitioners' spouses, preparedness to adopt a rural lifestyle, educational opportunities for children, and proximity to extended family and a socio-cultural network.

Not all Australian literature differentiates between the needs and preferences of internationally trained physicians and domestic physicians in rural contexts, however this does not mean that possible differences between the two groups are any less important to acknowledge. Internationally trained professionals - members of the Creative Class - such as IMGs may be especially concerned about proximity to extended family members and/or a co-ethno-cultural community. As previously noted, the lack of immigrant settlement services and the absence of ethnic support networks in rural regions have also been 
identified as deterrents for internationally trained professionals (Di Biase \& Bauder, 2005). Such observations are supported by Florida's Tolerance Index, which uses three key variables to measure a region's level of tolerance, including the proportion of immigrants or foreign-born residents, gays and lesbians, as well as the degree to which ethnic and racial groups are segregated from one another. While this index has been exclusively applied in an American context, the results are telling of what regions are most tolerant of diverse populations and lifestyle. Not surprisingly, large metropolitan cities such as San Diego, Miami and Las Vegas rank among the 'top 20' of the Tolerance Index. It is reasonable to assume that IMGs would be drawn to the more tolerant, urban areas for the same reasons as their migrant counterparts. However, as noted by Florida (2005) "a number of smaller regions ranked among the highest in Creative Class concentration," (p. 204) such as Gainesville, home to the University of Florida, East Lansing, home to Michigan State University and Madison, home to the University of Wisconsin. Such trends suggest that smaller - perhaps even more rural - areas have the potential to draw professionals including those whom are internationally trained, as argued by Walton-Roberts (2011). A stronger presence of ethnic diversity within these knowledge-based economies could be indicative of how certain communities successfully cater to the unique needs of internationally trained professionals and immigrants alike.

\subsection{Introducing the Canadian Case}

Canada averages 1 physician for every 450 residents and in rural settings this ratio is adjusted to 1 physician for every 3000 residents (Wilson, 2011). As previously mentioned, in an attempt to address the absence of physicians across rural and remote 
areas, some provinces and territories have collaborated with local health authorities to actively recruit IMGs. Over time, Canada's rural communities have not failed to recruit, but rather retain physicians who are well suited - professionally and personally - to rural environments

Identifying this characteristically unique population of physicians, that is, those who practice in rural settings beyond their initial contractual obligation, seems to be one of the most underrepresented research areas related to rural Canadian healthcare. Researcher and Dean of Medicine at Memorial University of Newfoundland James Rourke, has made significant efforts to close this research gap in Canadian literature. In keeping with American and Australian researchers' observations, Rourke (2005) found that ruralbased medical training plays a significant role in determining a physician's environmental preference for practice. Rourke's study (2005) observed that rural-based physicians are 2.4 times more likely to have previously lived in a rural environment than their urban counterparts, however differentiation between IMGs and Canadian Medical Graduates (CMGs) was not accounted for. While Rourke (2008) acknowledges that a higher percentage of IMGs practice in rural - as opposed to urban - environments $(26.3 \%$ and $21.9 \%$ respectively), he predicts that the percentage of IMGs practicing in rural settings is unlikely to increase. This may be indicative of mismatched recruitment efforts as the demand for rural physicians continues to grow and the majority of IMGs continue to return to urban settings post-contract (Dumont et al., 2008).

A qualitative study led by Anne Wong and Lynne Lohfeld (2008) led the authors to construct a 3-phase integration model based on interviews with 12 IMGs undergoing recertification in Ontario. The third phase, referred to as 'adaptation', chronicled coping 
strategies used while transitioning into the physician labour force. Participants identified the desire for mentorship and supervision, peer support from other IMGs in training, and sufficient time spent in training, the former of which would ensure an "increased sense of professional affiliation and autonomy, as well as familiarity with Canadian medical culture and society" (Wong \& Lohfeld 2008:57). Effectively, medical communities alike need to be equipped with the resources to facilitate integration, both on a technical and psychosocial level (Wong \& Lohfeld, 2008).

Canadian communities have the ability to offer these resources. Physicians considering rural practice in Canada are likely to experience a collegial environment, functioning group practice, supportive network with diverse specialty experience and have access to modern clinics and facilities (Rourke, 2008). Moreover, Rourke (2008) suggests that rural physicians have the opportunity, like their urban counterparts, to be stimulated and motivated by visiting medical students and residents. Finally, Rourke (2008) emphasizes the importance of the community environment, including "everything from the initial welcome to recreation and lifestyle, spousal employment opportunities and children's education" (p. 325). Furthermore, Emery et al. (2006) arrived upon a similar conclusion: "Policies aimed at improving the integration of qualified IMGs into the Canadian physician workforce should be an effective way to alleviate some of the current and expected shortages of physicians in Canada" (p. 167).

Largely absent from the broader selection of Canadian literature is the consideration of IMGs' training background. Little is known about the quantity and quality of "rural" experiences of IMGs during their undergraduate medical education or postgraduate medical training. Further understanding the environments within which 
IMGs have received training may provide more data to support efforts to boost rural practice and retention.

Finally, it is worth noting that the issue of equity has not been fully considered in directive policy decisions affecting the flow of IMGs to certain areas over others. It has been established that service agreements offer IMGs a pathway to full licensure, however, we must bear in mind that this often requires IMGs to settle in remote areas that lack key medical infrastructure, including peer mentor support networks, modern equipment and facilities. As immigrants, IMGs are expected to transition professionally and personally, involving change in all aspects of their lifestyle. While their preference may be to settle in more urban regions due to greater ethnic and cultural diversity, competition for positions especially Family Medicine - in these areas is high, even among Canadian medical graduates (Scott et al., 2009). As a result, the less desirable positions in rural communities are vacant and contracted out to IMGs looking to complete the licensing process. Equitable access to positions, which accommodate a physician's practice and lifestyle preferences, is not necessarily a reality for IMGs. When IMGs are involuntarily placed in environments that do not align with their training background and lifestyle preferences, it is possible that the delivery of health care may be compromised. While domestic graduates will be prioritized in both the residency matching and hiring processes, equitable opportunities for IMGs to practice in all areas is an underrepresented consideration that should be featured in future policy making. 


\section{CHAPTER THREE: RESEARCH DESIGN}

\subsection{Data}

In 1969, the Canadian Resident Matching Service (CaRMS) was established in an effort to provide medical students with a third party application system through which postgraduate residency training positions are delegated in a fair and transparent manner. Prior to the organization's inception, residency positions were assigned by the Canadian Association of Medical Students and sponsoring medical organizations collaborated under an advisory committee with the purpose of drafting and setting policies. In the early 1980's the Canadian Interns Matching Service (CIMS) evolved as a not-for-profit organization offering residency-matching services independent from medical organizations. CIMS was incorporated in 1994 and renamed Canadian Resident Matching Service.

As part of CaRMS's core mandate, the organization remains dedicated to advancing Canada's medical education system through unbiased data collection and analysis of its participants' career path selections. Data has been made available to medical educators, stakeholders, health authorities, policy makers and researchers in an effort to further stimulate discourse surrounding the Canadian healthcare experience. Interestingly, CaRMS has mobilized its resources to collect extensive data on IMGs and their career matches to residency positions across the country.

CaRMS data is publicly accessible, however permission to disseminate and reproduce materials is required. The request must detail how the data will be used and in what context. Upon receiving permission from the publisher, I was able to identify the relevant variables and retrieve the appropriate data for empirical analysis. The data and subsequent analysis does not identify specific individuals participating in CaRMS. 
Consistent and relevant variables were identified and accessible between 2011 and 2014, therefore limiting the data analysis to a four-year range.

\subsection{Research Questions}

From a review of the literature profiling IMGs in the United States, Australia and Canada, specific research questions were generated:

1. How has IMG participation in the domestic physician work force changed over time? Has it increased or decreased significantly in either rural or urban areas?

2. Why do certain IMGs stay in rural practice beyond contractual service agreements?

3. What are the demographics of IMGs?

a. In what country was their undergraduate medical education completed?

b. Did they complete postgraduate medical training in a rural community?

4. As the number of IMGs entering the postgraduate family medicine stream in Canada increases, how can provinces and territories improve the appeal of rural practice for IMGs?

5. What physician specialties are most critically needed in rural communities?

6. What programs or strategies are proving most successful in ameliorating the rural practice experience?

Available and relevant CaRMS data has been limited to: total participation rates, match and application rates, discipline match and application rates, residency placement rates by school, and IMG match and application from source countries. Within the data sets used, CaRMS did not differentiate between IMGs and Canadians studying abroad (CSAs). 
This limitation may skew certain data outputs as it represents a distinctly different population than foreign-born IMGs 


\section{CHAPTER FOUR: FINDINGS}

\subsection{IMG Participation and Match Rates}

Table 3 shows the number of IMGs matched to residency positions through CaRMS, with the percentage representing the number of matches as a fraction of total IMG participation. Over the last 4 years, the mean match rate for IMGs is calculated at $20.1 \%$ and for CMGs $96.5 \%$. The discrepancy between the two percentages clearly reflects Canadian health authorities' priority - placing close to $100 \%$ of Canadian applicants in residency positions across the country each year.

\begin{tabular}{|l|l|l|l|l|}
\hline & $\mathbf{2 0 1 4}$ & $\mathbf{2 0 1 3}$ & $\mathbf{2 0 1 2}$ & $\mathbf{2 0 1 1}$ \\
\hline IMG & 449 & 499 & 407 & 380 \\
\hline \% & 19.4 & 22.5 & 18.9 & 19.7 \\
\hline CMG & 2779 & 2645 & 2622 & 2507 \\
\hline \% & 95.8 & 96.3 & 96.5 & 97.3 \\
\hline
\end{tabular}

Table 3. Percentage and number of matched IMGs from 2011-2014

Table 3 also illustrates a slightly higher IMG match ratio in 2013 (22.5\%), representing a $22.6 \%$ increase from 2012. Figure 1 depicts the annual distribution of IMG matches as a portion of total IMG participants. Interestingly, there has been a $20.7 \%$ increase in IMG applicants and an 18.2\% increase in IMG matches through CaRMS between 2011 and 2014. It is possible that the higher match ratio in 2013 can be attributed to the increased number of IMGs applying for positions in Family Medicine, Internal Medicine and Pediatrics, streams of medicine that typically exhibit the largest concentrations of IMG applicants. 


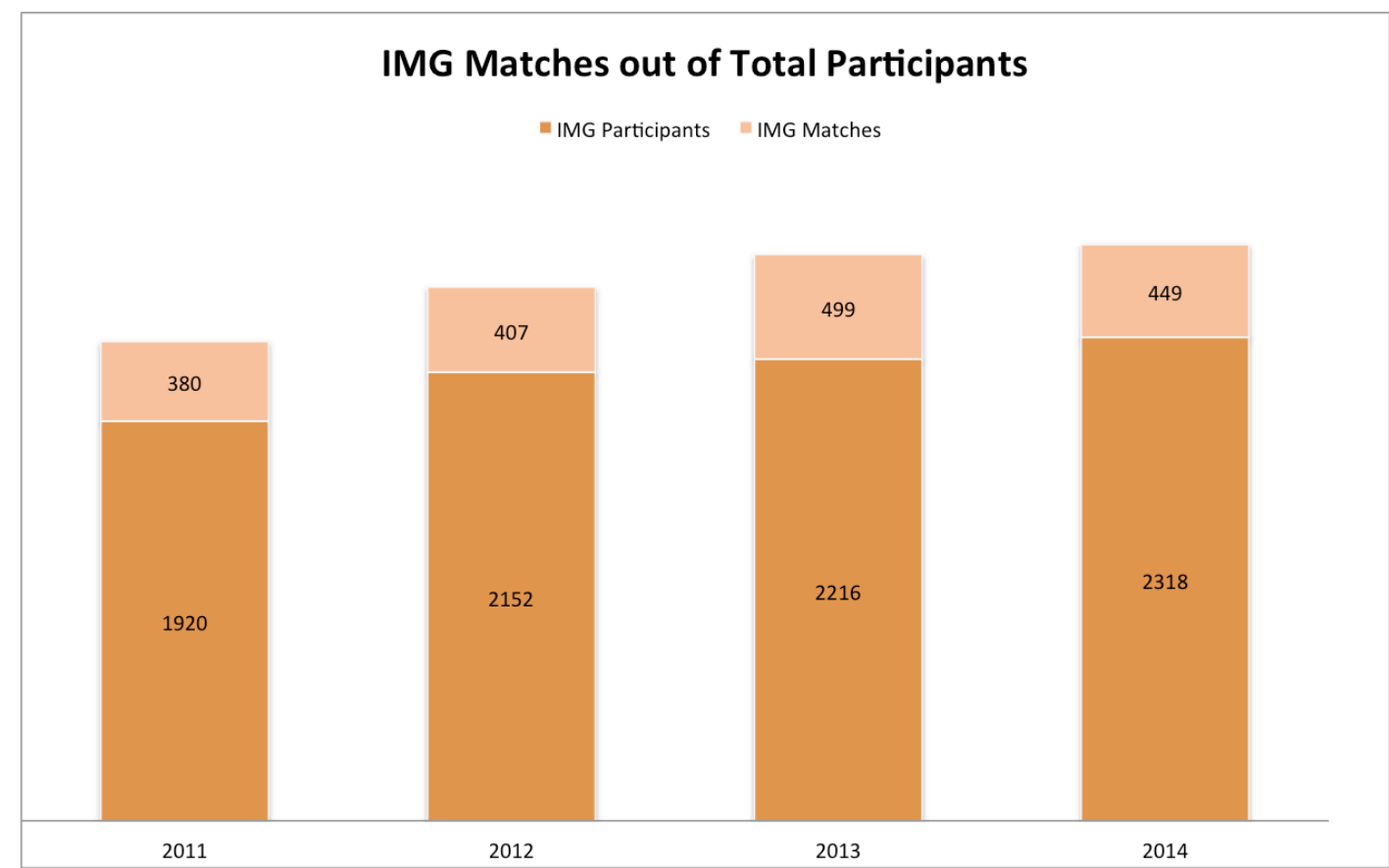

Figure 1. The number of IMG applicants and IMG matches made through CaRMS between 2011 and 2014

\subsection{IMG Discipline Choice and Preference}

As illustrated in Table 4, between 2012 and 2013 there was a 17.6\% increase in applicants to Family Medicine, $14.5 \%$ in Internal Medicine and 6.6\% in Pediatrics. The percentage increases for the same streams between $2011 / 2012$ (9.9\%, 13\% and 7.1\% respectively) represent more modest application rates. Similarly, between 2013 and 2014 there were only very modest increases in Family Medicine and Internal Medicine applications ( $4.6 \%$ and $0.5 \%$, respectively), and a decrease in applicants to Pediatrics by $4.8 \%$.

\begin{tabular}{|l|l|l|l|}
\hline Year & Family Medicine & Internal Medicine & Pediatrics \\
\hline 2014 & 2206 & 1072 & 398 \\
\hline 2013 & 2108 & 1066 & 418 \\
\hline 2012 & 1793 & 931 & 392 \\
\hline 2011 & 1632 & 824 & 366 \\
\hline
\end{tabular}

Table 4. Number of IMG Applicants to Family Medicine, Internal Medicine and Pediatric Residency Positions 2011-2014 
The growing number of applicants to Family Medicine is an encouraging observation. As previously discussed, Family Medicine (otherwise referred to as General Practice) is a 'malleable' primary care specialty; it has a wide scope of practice and provides opportunities to work in an array of environments, particularly rural communities where a broad and diverse skillset is required. A more in-depth analysis of the CaRMS Family Medicine application cohort may provide more insight to help identify physicians inclined to practice in rural environments.

CaRMS data indicates that IMG applicants have shown an increasing interest in the Family Medicine stream, as illustrated in Table 4. This finding is consistent with the observations derived from 2002 CaRMS data by Szafran et al. (2005). When medical graduates apply to CaRMS for residency positions, they are asked to rank their program preferences according to their professional interests. Most graduates are matched in the 'first iteration' based on their match preferences. For those not matched in the first iteration, a second iteration occurs shortly thereafter, giving unsuccessful applicants a chance to reorder their rankings in accordance to the remaining residency vacancies. It is evident that in comparison to their Canadian counterparts, IMGs are significantly more likely to choose Family Medicine as their first choice discipline. Interestingly, the figures presented in Table 5 also illustrate an increasing commitment to Family Medicine, with a relative increase of 39.6\% (between 2011 and 2014) in the proportion of IMGs selecting Family Medicine as their first choice discipline. Comparatively, there was a relative increase of 26.5\% for CMGs selecting Family Medicine as their first choice discipline. 


\begin{tabular}{|l|l|l|}
\hline Family Medicine as $1^{\text {st }}$ Choice & IMG & CMG \\
\hline 2014 & $51.3 \%$ & $38.2 \%$ \\
\hline 2013 & $49.2 \%$ & $36.3 \%$ \\
\hline 2012 & $49.5 \%$ & $34.6 \%$ \\
\hline 2011 & $46.8 \%$ & $34.0 \%$ \\
\hline
\end{tabular}

Table 5. Percentage of IMGs and CMGs Selecting Family Medicine as First Choice Discipline

These observations are important as they potentially identify a pool of family physicians that possess an appropriate skillset for rural environments. Incitti et al. (2003) compared the skillset of 507 rural family physicians with a random selection of 513 urban physicians in Ontario and found that family physicians practicing in rural areas had a broader range of clinical and procedural skills including obstetrics, anesthesia and emergency medicine in addition to their office duties, nursing home care and house call responsibilities. The increasing number of entrants into Family Medicine does not however necessarily mean that the there is a growing interest in rural practice.

\subsection{Residency Training Locations and Distribution}

The Northern Ontario School of Medicine is relatively new and has an established program with a focus on rural medicine. As Canada's newest Family Medicine program, ROCS (Residents of the Canadian Shield) offers a plethora of training sites in Northern Ontario, with 85 rural, remote, Aboriginal and Francophone communities from which to choose. Efforts to more broadly market these locations as viable options for residency placements through popular matching services such as CaRMS could serve to attract a greater number of medical graduates interested in rural medicine and practice. Table 6 illustrates the universities - as listed by CaRMS - that offer designated Rural Family Medicine residency programs or streams. 


\begin{tabular}{|l|l|}
\hline University of British Columbia & University of Calgary \\
\hline University of Alberta & University of Saskatchewan \\
\hline University of Manitoba & University of Western Ontario \\
\hline McMaster University & Northern Ontario School of Medicine \\
\hline University of Toronto & Queen's University \\
\hline University of Ottawa, Sudbury & Memorial University of Newfoundland \\
\hline
\end{tabular}

Table 6. Universities with designated Rural Family Medicine programs

Table 7 below shows the portion of IMGs matched with a Family Medicine residency as a percentage of the total available positions at each institution. Notably, the Northern Ontario School of Medicine (NOSM) has had on average a reasonably high match rate for IMGs to Family Medicine positions. However each year only two IMGs were matched; in 2011 and 2012 the two available positions were matched by successful IMG candidates. In 2013 and 2014 two Family Medicine positions out of the three available residency positions were filled, reducing the match rates for those years.

\begin{tabular}{|l|l|l|l|l|}
\hline Universities with Designated Rural Program & $\mathbf{2 0 1 4}$ & $\mathbf{2 0 1 3}$ & $\mathbf{2 0 1 2}$ & $\mathbf{2 0 1 1}$ \\
\hline University of Alberta & $37.5 \%$ & $33.3 \%$ & ---- & ---- \\
\hline University of Manitoba & $64.7 \%$ & $61.1 \%$ & $57.9 \%$ & $50.0 \%$ \\
\hline McMaster University & $37.5 \%$ & $35.3 \%$ & $33.3 \%$ & $41.4 \%$ \\
\hline University of Toronto & $33.8 \%$ & $34.3 \%$ & $35.8 \%$ & $36.4 \%$ \\
\hline University of Ottawa, Sudbury & $38.2 \%$ & $35.3 \%$ & $34.2 \%$ & $38.2 \%$ \\
\hline University of Calgary & $50.0 \%$ & $50.0 \%$ & ---- & ---- \\
\hline University of Saskatchewan & $82.1 \%$ & $81.5 \%$ & $84.6 \%$ & $33.3 \%$ \\
\hline University of Western Ontario & $52.6 \%$ & $52.8 \%$ & $54.3 \%$ & $54.5 \%$ \\
\hline Queen's University & $52.6 \%$ & $57.9 \%$ & $57.9 \%$ & $57.9 \%$ \\
\hline University of British Columbia & $87.8 \%$ & $82.3 \%$ & $83.3 \%$ & $72.2 \%$ \\
\hline Memorial University of Newfoundland & $66.7 \%$ & $80.0 \%$ & $57.1 \%$ & $66.7 \%$ \\
\hline Northern Ontario School of Medicine & $66.7 \%$ & $66.7 \%$ & $100.0 \%$ & $100.0 \%$ \\
\hline
\end{tabular}

Table 7. Percentage of IMGs Matched to Family Medicine in First Iteration 2011-2014

The University of Saskatchewan, comparatively, exhibited relatively high match rates after 2011. In 2011, just 1 IMG matched to a Family Medicine position out of the three IMG-allotted residencies available. In 2012 however, 11 out of the 13 available residencies were filled by IMG Family Medicine residents. This figure doubled in 2013, with 22 IMG Family Medicine positions being filled out of the 27 available residencies. 2014 saw similar 
numbers to the previous year with 23 IMG Family Medicine positions filling out of 28 available IMG-designated residencies. Between 2011 and 2014 the number of available residencies for IMGs - across all disciplines - increased more than 9 times the original allotment.

What were the reasons for the dramatic increase from just one IMG matching to a Family Medicine position in 2011 to 22 IMGs matching in 2014? The University of Saskatchewan's College of Medicine admissions webpage distinguishes between the IMG and CMG application process. The website explains that upon matching to a residency position at the University of Saskatchewan, IMGs are required to attend a six-week assessment and orientation program in which provides coaching, instruction and mentoring specifically geared towards IMGs and their needs. The program offers IMGs an opportunity to become familiar with not only Canadian medical practices but also the unique context in which they will train and practice in the province; an introduction to resources including individuals, groups and organizations that can offer further assistance throughout residency training with a clear understanding of expectations as they progress through the program.

The University of Saskatchewan offers an appealing residency pathway that is mindful of IMGs' unfamiliarity with Canadian medical protocols, education, and lifestyle. It is interesting to note that the Department of Family Medicine at the University of Saskatchewan states: "Our social accountability mandate is to train family physicians to care for the health needs of the underserved, urban, rural, and remote populations" (Department of Family Medicine, 2014). It is possible that programs in which train IMGs 
from a 'rurally biased' perspective may have success in boosting the appeal of rural medicine.

\subsection{IMG Source Countries and Regional Distribution}

After 2011, the total number of IMG participants from countries in Asia - the top source region in 2011 - declined consistently, while the number of IMGs from Central America/Caribbean rose steadily, surpassing all other regions by 2014. From 305 participants in 2011 to 528 in 2014 (Figure 2), this trend is consistent with Young et al.'s (2012) findings of the increasing number of licensed IMGs from the Caribbean region. Young et al. (2012) found that "[w]hile the total number of IMGs with an active license in the United States increased by only $4 \%$ since 2010 , the number of physicians who graduated from a school in the Caribbean increased during that time period by $14 \% "$ (p.15). A similar observation can be made using CaRMS data. Between 2011 and 2014, CaRMS experienced a 20.7\% increase in IMG applicants across all regions, however most notably, a 73.1\% increase in applicants from the Central America/Caribbean region.

Figure 2 illustrates the growing trend of IMG participants from Central America and the Caribbean between 2011 and 2014, including both the number of successful residency matches and total participation. It is important to note that a significant portion of IMGs participating in the CaRMS matches may be Canadian citizens returning from medical school abroad. This distinction was not made in the CaRMS data set and limits the generalizability of my findings. Evidently, these groups are different in most respects as one group is "coming home" to a familiar culture, language and system while the other is 
quite literally moving into opposite circumstances, leaving behind their culture, language and system.

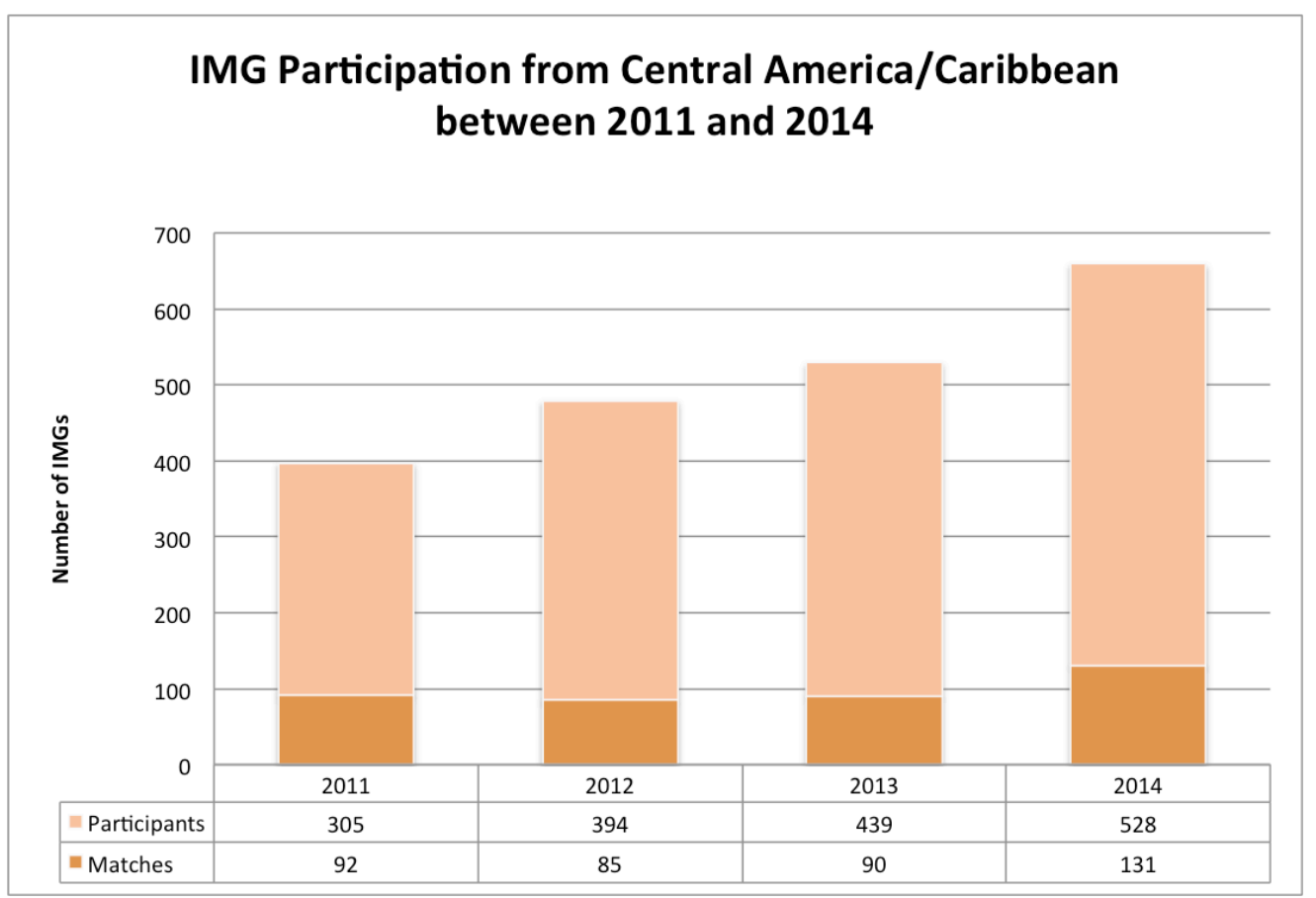

Figure 2. Trends in Central American/Caribbean IMG participation through CaRMS

CaRMS data provided the numbers of IMG participants and matches from the following regions: Africa, Asia, Central America/Caribbean, Europe, Middle East, North America, Oceania/Pacific Islands and South America. Figures 3, 4, 5 and 6 show the regional distribution of IMGs, including the number of matches - across all disciplines - out of the total number of IMG participants per annum between 2011 and 2014. The European region maintained an average of 457 applicants between 2011 and 2014 with little variance, and had the highest average match $\operatorname{rate}^{3}$ (31.5\%). However the Central America/Caribbean region produced more participants than Europe in 2014 and had the second highest average match rate (24.3\%) between 2011 and 2014.

\footnotetext{
${ }^{3}$ Number of IMGs matched to a residency position out of total IMG applicants
} 


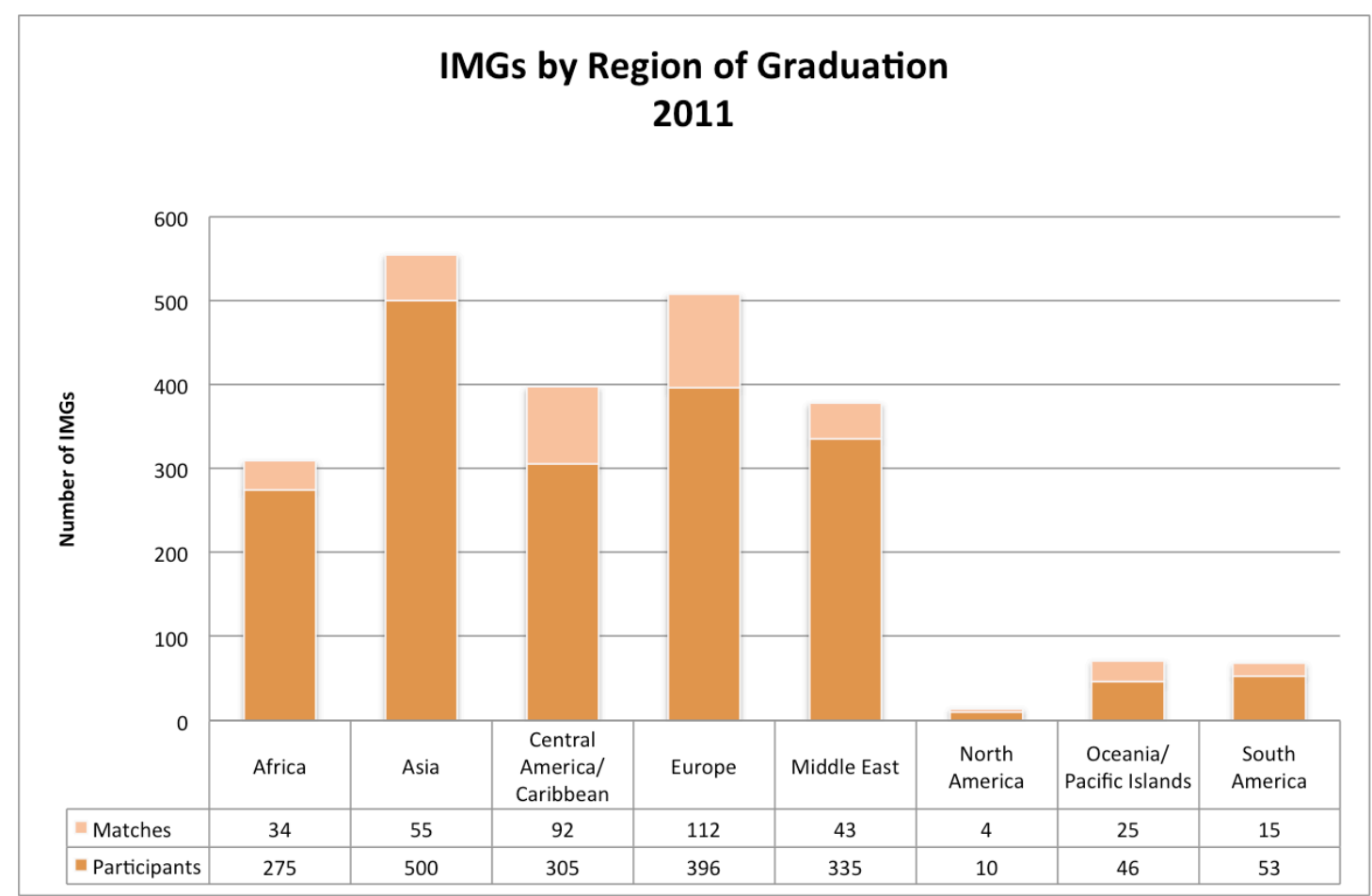

Figure 3. 2011 IMG source countries, number of IMG participants and matches

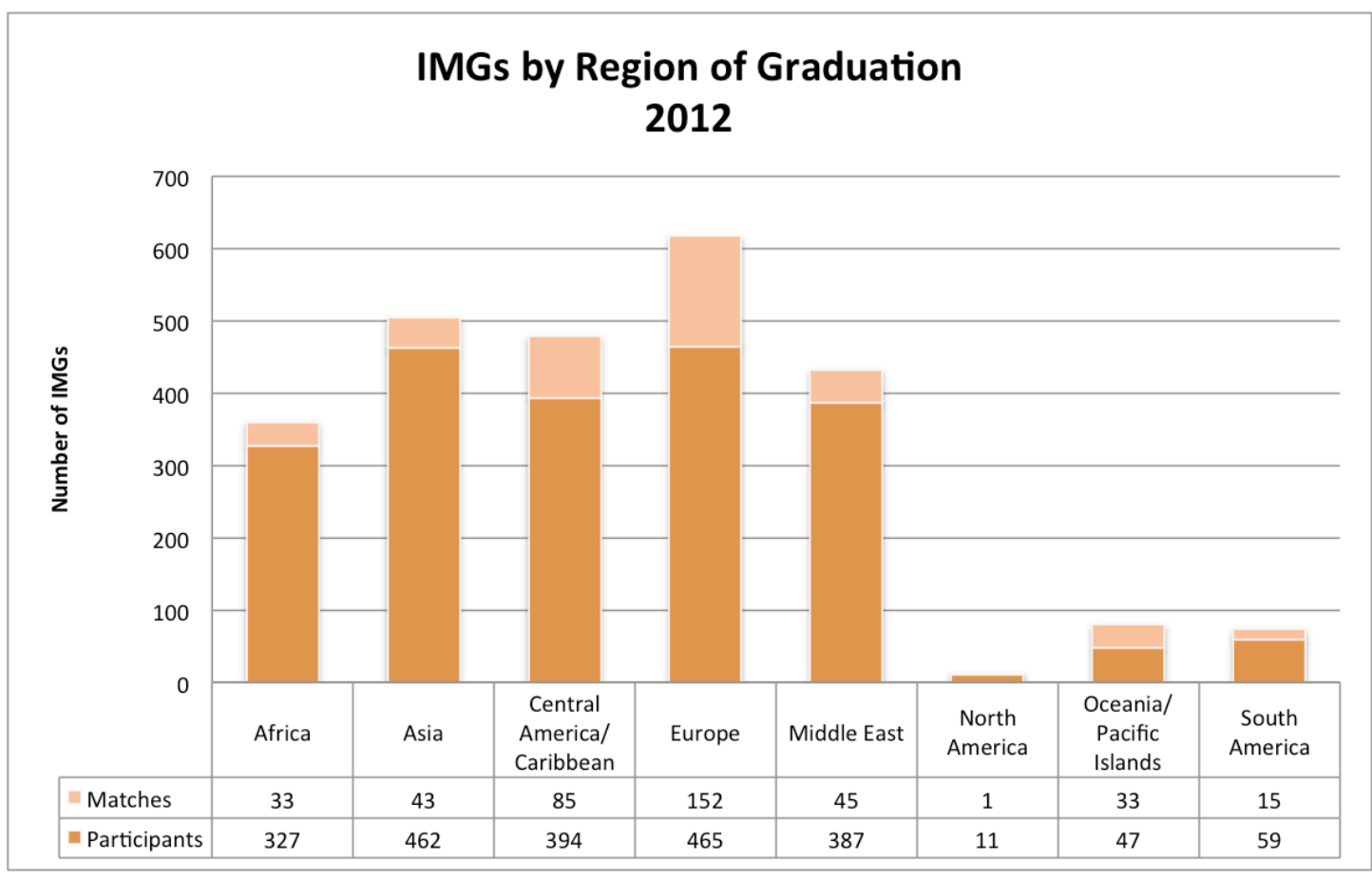

Figure 4. 2012 IMG source countries, number of IMG participants and matches 


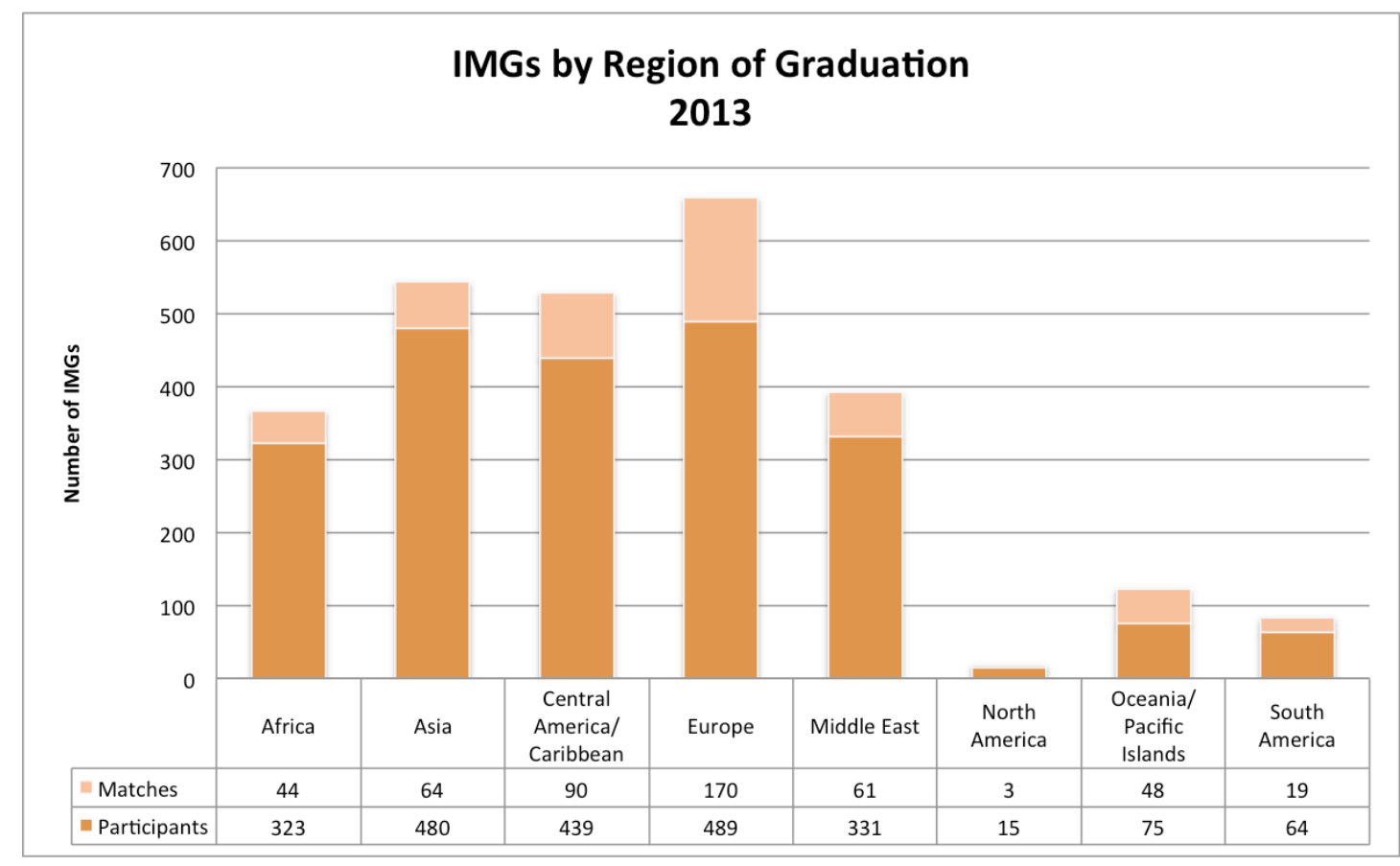

Figure 5. 2013 IMG source countries, number of IMG participants and matches

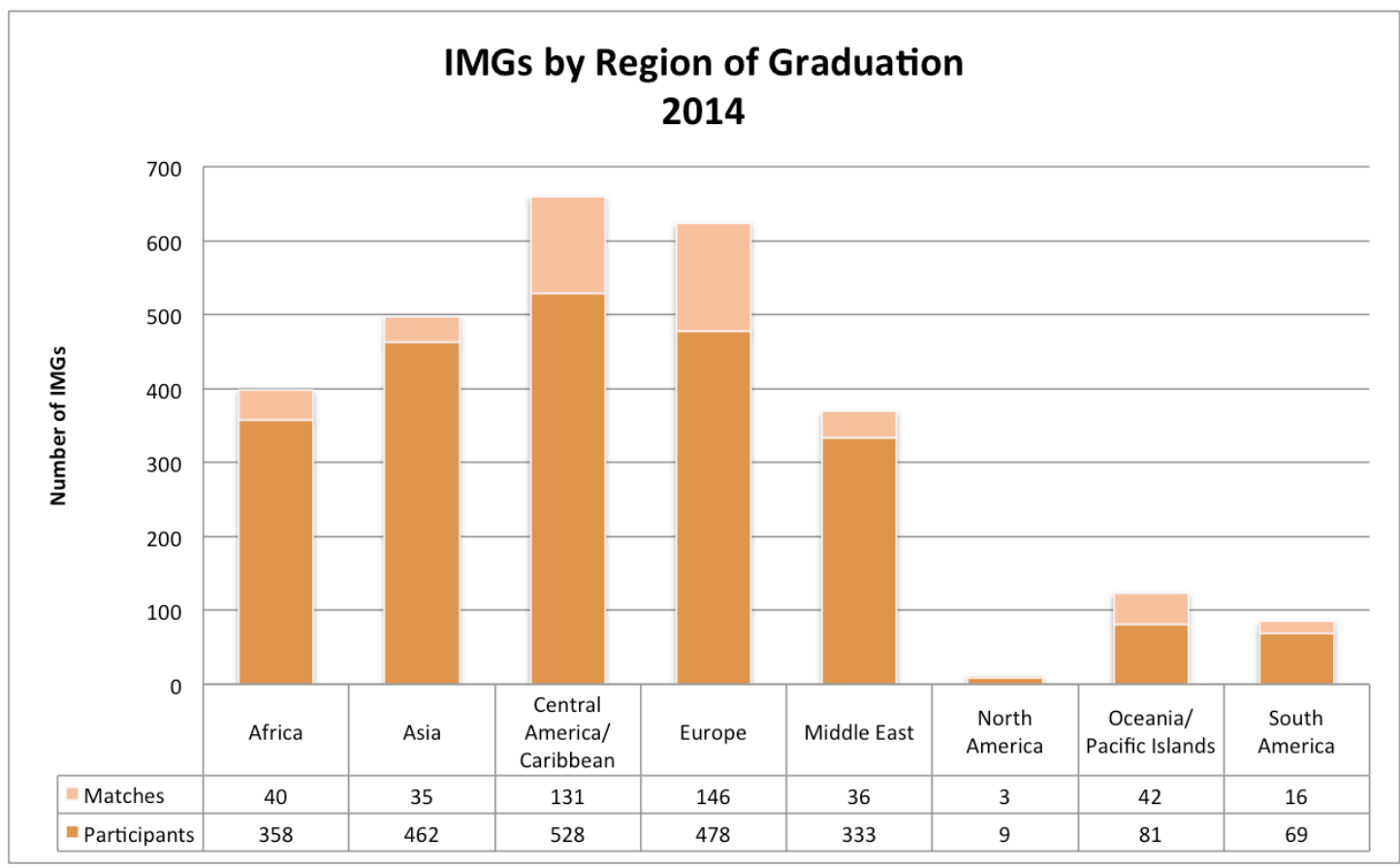

Figure 6. 2014 IMG source countries, number of IMG participants and matches 
These trends illustrated Figures $2-6$ are similar to observations noted in the United States. Eckhert (2010) found that a growing number of Canadian and US-born citizens look to "offshore medical schools" (OMSs) most of which are located in the Caribbean region and have been purposed to educate and train North American students with the intention that they return home for practice. OMS graduates are attractive in that they are not subject to as arduous reaccreditation process as their international counterparts due to the fact that OMSs are - more often than not - recognized by North American regulatory bodies (Eckhert, 2010). An increasing supply of graduates from schools in this region is an important trend to make note of from a policy point of view. As these OMSs are often 'extensions' of preexisting institutions in North America, it may be feasible for domestic health authorities to advocate for the introduction of distinctive rural medicine streams in undergraduate programs. Upon returning home for residency training, some graduates may find themselves inclined to explore rural practice as a long-term possibility. 


\section{CHAPTER FIVE: DISCUSSION \& CONCLUSION}

Constructing a profile for IMGs in a rural, Canadian context is a complex and challenging task. There are many variables at play: the geographical distribution of residency positions, source countries, previous institutions attended by graduates, admittance rates, training infrastructure and the variability of physician needs and resources, to name a few. The investigative process of understanding and identifying a distinct group of IMGs prepared and willing to pursue rural practice is evolving as information and data continues to be disseminated and analyzed by researchers. CaRMS has proven to be a valuable, publicly accessible source of data relevant to IMG postgraduate training, the final step before full licensure.

The core issue and challenge relates to attracting sufficient numbers of medical graduates with an interest in not only rural medicine but also the rural lifestyle. Various studies (Rabinowitz et al., 2005; Curran \& Rourke, 2004; Dunbabin \& Levitt, 2003; Brooks et al., 2002; Woloschuk \& Tarrant, 2002) have identified certain variables that impact a physician's decision to practice in a rural environment including coming from a rural background, having exposure to rural medical education and/or training. A research/knowledge gap persists in understanding what factors predictably influence retention in rural communities, a gap that is even wider in the context of IMGs. Yet regardless of an IMG's training background - rural or urban-based - their needs as both newcomers and trainees must be met in order to facilitate a successful transition into the physician labour force. As it has been found in other countries (Allen et al., 2013), it is essential for residency programs to recognize the non-technical aspects of IMG training, "such as differences in communication roles and style, medical ethics, doctor-patient 
relationships, and cultural, medical organizational and medical practices" (Wong \& Lohfeld 2008, p. 58).

Boyd and Schellenberg (2007) found that just over half (55\%) of IMGs end up working as physicians, compared to $90 \%$ of the Canadian-born and educated physicians. Consequently, approximately $33 \%$ of internationally educated physicians work in unrelated occupations (Boyd \& Schellenberg, 2007). Canadian health authorities have identified the need for a more even distribution of health care services across the country (Scott et al., 2009). The means through which this distribution is achieved remains answered. Dumont et al. (2008) observed that in the absence of incentives, IMGs are more likely to settle in urban hubs such as Toronto and Montreal, a trend that follows the general settlement patterns of fellow non-medical newcomers. As such, Ontario and Quebec exhibit denser concentrations of IMGs in their urban centers but have fewer numbers of IMGs overall, compared to Alberta, British Columbia, Manitoba and Saskatchewan (Dumont et al., 2008). In the latter provinces, IMGs have been especially vital to the delivery of health care across their vast and remote landscapes (Dumont et al, 2008).

The high density of IMGs in urban centers can in part be explained by what Florida calls "means migration," that is, the relocation of highly skilled and educated professionals to metropolitan - as opposed to rural - regions as a result of the perceived assumption that such areas yield ample employment opportunity (Florida, 2012). Acknowledging that under the Canadian Charter of Rights and Freedoms citizens and permanent residents alike cannot be bound to certain regions, government and health authorities have limited abilities in directing the flow of physicians into underserved regions. With that being said, the role of universities and higher learning institutions in rural communities and smaller 
cities and towns should not be underestimated. These institutions are appealing in terms of the educational and employment resources they offer, and greater diversity in the surrounding population (Walton-Roberts, 2005). Similarly, Bauder (2003) has argued that when incentivizing rural settlement, policy makers must be mindful of how such environments 'fit' and benefit immigrants themselves, "not only the benefits to local communities" (p. 198). It is possible that rural-based university towns may appeal as a more desirable environment for IMGs who seek professional guidance, further educational opportunities and personal support networks.

Of equal importance and relevance, future research may consider addressing questions such as: Do some countries have larger concentrations of medical schools offering rural medical education and exposure than others? Does this mean migrants from these institutions would be more likely to stay in rural practice in Canada? Although these questions extend well beyond both the data made accessible by CaRMS and the scope of this paper, they identify critical research gaps that must be addressed in an effort to complete the rural IMG profile, that is, IMGs who would voluntarily pursue rural medicine as their Canadian career path.

Ontario made several efforts to increase opportunities for IMGs and promote rural practice in the province's underserved communities. The Rural Northern Physician Group Agreement endorses a funding model for the provision of health care in remote communities available to physicians practicing in any of the 39 underserved communities in Ontario (Dumont, 2008). Additionally, Ontario also supports the Underserviced Area Program (UAP) that offers financial grants up to $\$ 40,000$ for physicians offering full-time 
healthcare services over a four-year period in northern Ontario communities (Barnighausen \& Bloom, 2009).

Alberta has been successful in recognizing the full picture of IMG settlement and associated retention issues. The province is taking measures to accommodate physicians' families in their Rural Physician Spousal Programming as part of the Alberta Rural Physician Action Plan (Dumont, 2008). On licensing, the Alberta International Medical Graduate program (AIMG) established in 2001 by Alberta Health and Wellness has yielded promising numbers of fully-licensed physicians (Emery et al., 2005). AIMG offers residency positions to qualified IMGs who have met the standard requirements, but also provides a standardized assessment of clinical skills and two comprehensive behavioural interviews to help provide the most appropriate working environment for each candidate. Interestingly, Emery et al. (2005) observed, "The expenditures on assessment and selection processes are directly comparable to the resources allocated to a student in a Canadian undergraduate medical school program as the output from both streams is a 'residency ready' graduate" (p. 167). Further analysis revealed that the cost per year for the training of one Canadian medical student was equal to 2.5 AIMG 'residency ready' physicians (Emery et al, 2005). Investment therefore in infrastructure that would allow programs such as the AIMG to conduct multidimensional assessments of IMG education and experience has the potential to further develop a rural physician profile.

As an increasing number of IMGs pursue opportunities in Family Medicine, it would be interesting to examine the impact of programs that have a 'rural bias' - such as the University of Saskatchewan residency program - and whether they effectively heighten interest and retention in rural practice among IMGs. The University of Washington in 
Seattle, as previously mentioned, followed up with graduates of their rural medicine residency program and found that a majority stayed in rural practice thereafter. To date, no such follow up exists for Canadian rural-based residency programs.

Further developing comprehensive IMG postgraduate training programs will be necessary as the demand for generalists continues to rise in rural communities across Canada. As identified in CaRMS data, the growing pool of family residency positions and applicants means that more physicians have the potential to be exposed to rural medicine and practice through rotations in smaller communities, which may in turn improve recruitment and retention rates to rural medical practice. It should be noted that although CaRMS has provided a wealth of information regarding discipline choice for both IMGs and CMGs, access to data on the practice location preferences of medical graduates was not available.

As a possible recommendation, the addition of Rural Medicine as a separate discipline in CaRMS or as a one year fellowship for Family Medicine residents could help develop an explicit path for those with a specific interest in Canadian rural medicine. Some Australian literature (Smith \& Hays, 2004) suggests that there is cause to distinguish Rural Medicine as a completely separate discipline from more urban-centric medicine streams. Smith and Hays (2004) argue that "[t]he strongest differences are seen in the patient care domain, as here additional knowledge and skills are required to replace those normally provided by others" (p. 69). Furthermore, rural physicians also must professionally manage their work environment around close-knit teams and maintain solid networks of peer communication (Smith \& Hays, 2004). As such, future research on IMG profiling in the 
Canadian context may benefit from observing the skills and characteristics of physicians entering Rural Medicine streams.

Collectively, Australian, American and Canadian research has determined that looking to the skills and expertise of IMGs has enormous potential in addressing medical care shortages across vast landscapes. In a publication on behalf of the Institute for Research on Public Policy, Alboim et al. (2005) argue that Canada stands to gain from identifying "what is required to bring the individual's standing up to the Canadian equivalent, in order to allow the individual to practice his or her occupation in Canada or to otherwise realize the maximum benefit from the schooling and experience held at the time of arrival..." (p. 16). As health authorities and stakeholders alike bear the weight of addressing the country's intensifying health service shortages, we must remind ourselves that examining the needs of Canada's population includes looking at and addressing the needs of international medical graduates themselves. 


\section{REFERENCES}

Alboim, N., Finnie, R., \& Meng, R. (2005) The discounting of immigrants' skills in Canada: evidence and policy recommendations. Choices, 11(2), 1-23.

Allen, S. M., Ballweg, R. A., Cosgrove, E. M., Engle, K. A., Robinson, L. R., Rosenblatt, R. A. \& Wenrich, M. D. (2013). Challenges and opportunities in building a sustainable rural primary care workforce in alignment with the Affordable Care Act: the WWAMI program as a case study. Academic Medicine, 88(12), 1862-1869.

Altbach, P. G., \& Knight, J. (2007). The internationalization of higher education: Motivations and realities. Journal of Studies in International Education, 11(3-4), 290-305.

Arah, O. A., Ogbu, U. C., \& Okeke, C. E. (2008). Too poor to leave, too rich to stay: developmental and global health correlates of physician migration to the United States, Canada, Australia, and the United Kingdom. American Journal of Public Health, 98(1), 148.

Association of Faculties of Medicine of Canada. (2012). International Medical Graduates and Canadians Studying Medicine Abroad. Retrieved from https://www.afmc.ca/pdf/datapoint/DATAPOINT-nov2012-Eng.pdf

Audas, R., Ryan, A., \& Vardy, D. (2008). Where did the doctors go? A study of retention and migration of provisionally licensed international medical graduates practising in Newfoundland and Labrador between 1995 and 2006. Canadian Journal of Rural Medicine, 14(1), 21-24.

Bach, S. (2008). International mobility of health professionals: Brain drain or brain exchange? The international mobility of talent: Types, causes, and development impact. Oxford: Oxford University Press, 202-235.

Bärnighausen, T., \& Bloom, D. E. (2009). Financial incentives for return of service in underserved areas: a systematic review. BMC Health Services Research, 9(1), 86.

Bauder, H. (2003). Immigrants in urban labour markets: place of birth and immigrant concentrations in British Columbia. Canadian Journal of Urban Research, 12(2), 179-204.

Boulet, J. R., Norcini, J. J., Whelan, G. P., Hallock, J. A., \& Seeling, S. S. (2006). The international medical graduate pipeline: recent trends in certification and residency training. Health Affairs, 25(2), 469-477.

Boyd, M., \& Schellenberg, G. (2007). Re-accreditation and the occupations of immigrant doctors and engineers. Canadian Social Trends, 84, 1-10. 
Brooks, R. G., Walsh, M., Mardon, R. E., Lewis, M., \& Clawson, A. (2002). The roles of nature and nurture in the recruitment and retention of primary care physicians in rural areas: a review of the literature. Academic Medicine, 77(8), 790-798.

Buske, L. (2008). Rural Reality: Analyzing Medical Life Outside Canada's Cities. Canadian Medical Association. Retrieved from http://www.cma.ca.

Buske, L. M., Yager, S. N., Adams, O. B., Marcus, L., \& Lefebvre, F. A. (1999). Rural community development tools from the medical perspective: A national framework of rurality and projections of physician workforce supply in rural and remote areas of Canada. Ottawa, ON: Canadian Medical Association.

Canadian Institute for Health Information. (2009). International Medical Graduates in Canada: 1972 to 2007. Ottawa, ON: Canada.

Canadian Institute for Health Information. (2012). Supply, distribution and migration of Canaian physicians, 2012. Ottawa, ON: Canada. Government of Canada Publications.

Curran, V., \& Rourke, J. (2004). The role of medical education in the recruitment and retention of rural physicians. Medical Teacher, 26(3), 265-272.

Dauphinee, W. D. (2005). Physician migration to and from Canada: The challenge of finding the ethical and political balance between the individual's right to mobility and recruitment to underserved communities. Journal of Continuing Education in the Health Professions, 25(1), 22-29.

Di Biase, S., \& Bauder, H. (2005). Immigrant Settlement in Ontario Location and Local Labour Markets. Canadian Ethnic Studies, 37(3), 114-134.

Dill, M. J., \& Salsberg, E. S. (2008). The complexities of physician supply and demand: projections through 2025. Association of American Medical Colleges. 1-77.

Dove, N. (2009). Can international medical graduates help solve Canada's shortage of rural physicians. Canadian Journal of Rural Medicine, 14(3), 120-123.

Dunbabin, J., \& Levitt, L. (2003). Rural origin and rural medical exposure: their impact on the rural and remote medical workforce in Australia. Rural and Remote Health, 3(1), 212.

Eckhert, N. L. (2010). Perspective: private schools of the Caribbean: outsourcing medical education. Academic Medicine, 85(4), 622-630.

Emery, J. C., Crutcher, R. A., Harrison, A., \& Wright, H. (2006). Social rates of return to investment in skills assessment and residency training of international medical graduates in Alberta. Health Policy, 79(2), 165-174. 
Family Medicine R3 Emergency Resident Medical Training Agreement. (2011).

Accommodations for Short Term Rotations. Retrieved from

http://www.medicine.usask.ca/education/medical/postgrad/information-

sheets/2014\%20R3\%20R0S\%20Agreement.pdf.

Florida, R. (2006). The Flight of the Creative Class: The New Global Competition for Talent. Liberal Education, 92(3), 22-29.

Florida, R. L. (2012). The rise of the creative class: revisited. New York, NY: Basic Books.

Frehywot, S., Mullan, F., Payne, P. W., \& Ross, H. (2010). Compulsory service programmes for recruiting health workers in remote and rural areas: do they work?. Bulletin of the World Health Organization, 88(5), 364-370.

Geyman, J. P., Hart, L. G., Norris, T. E., Coombs, J. B., \& Lishner, D. M. (2000). Educating generalist physicians for rural practice: how are we doing?. The Journal of Rural Health, 16(1), 56-80.

Greenaway, S. M. (2011). The Attractiveness of Return-for-service Bursary Programs to Medical Students in Newfoundland and Labrador (Doctoral dissertation). Retrieved from http://phdtree.org/pdf/25942844-the-attractiveness-of-return-for-service-bursaryprograms-to-medical-students-in-newfoundland-and-labrador/.

Grobler, L., Marais, B. J., Mabunda, S. A., Marindi, P. N., Reuter, H., \& Volmink, J. (2009). Interventions for increasing the proportion of health professionals practising in rural and other underserved areas. Cochrane Database Systematic Reviews, 1(1).

Grover, A. (Producer). (2013, November). Graduate medical education and the physician workforce. Retrieved from http://vimeo.com/77727683.

Haggblade, S., Hazell, P., \& Reardon, T. (2010). The rural non-farm economy: prospects for growth and poverty reduction. World Development, 38(10), 1429-1441.

Han, G. S., \& Humphreys, J. S. (2005). Overseas-trained doctors in Australia: Community integration and their intention to stay in a rural community. Australian Journal of Rural Health, 13(4), 236-241.

Henry, J. A., Edwards, B. J., \& Crotty, B. (2009). Why do medical graduates choose rural careers?. Rural \& Remote Health, 9(1), 1083.

Incitti, F., Rourke, J., Rourke, L. L., \& Kennard, M. (2003). Rural women family physicians. Are they unique?. Canadian Family Physician, 49(3), 320-327.

Iredale, R. (2001). The migration of professionals: theories and typologies. International Migration, 39(5), 7-26. 
Jones, J., Hugo, G., Bamford, E., Jones, M., Humphreys, J., \& Taylor, D. (2001). A critical review of rural medical workforce retention in Australia. Australian Health Review, 24(4), 91.

Laven, G. A., Beilby, J. J., Wilkinson, D., \& McElroy, H. J. (2003). Factors associated with rural practice among Australian-trained general practitioners. Medical Journal of Australia, $179(2), 75-80$.

Mathews, M., Edwards, A. C., \& Rourke, J. T. (2008). Retention of provisionally licensed international medical graduates: a historical cohort study of general and family physicians in Newfoundland and Labrador. Open Medicine, 2(2), 62.

McGrath, P., Henderson, D., \& Phillips, E. (2012). Integration into the Australian health care system: insights from international medical graduates. Australian Family Physician, 38(10), 133-139.

McGrath, P., Wong, A., \& Holewa, H. (2011). Canadian and Australian licensing policies for international medical graduates: a web-based comparison. Education for Health, 24(1), 1523.

Pong, R. W., \& Heng, D. (2005). The link between rural medical education and rural medical practice location: literature review and synthesis. Sudbury, ON: Laurentian University.

Rabinowitz, H. K., Diamond, J. J., Markham, F. W., \& Rabinowitz, C. (2005). Long-term retention of graduates from a program to increase the supply of rural family physicians. Academic Medicine, 80(8), 728-732.

Rourke, J. (2005). Relationship between practice location of Ontario family physicians and their rural background or amount of rural medical education experience. Canadian Journal of Rural Medicine, 10(4), 231-239.

Rourke, J. (2008). Increasing the number of rural physicians. Canadian Medical Association Journal, 178(3), 322-325.

Ruddy, G. R., Fryer, G. E., Phillips, R. L., Green, L. A., Dodoo, M. S., \& McCann, J. L. (2005). The family physician workforce: the special case of rural populations. American Family Physician, 72(1), 147.

Saskatchewan Chamber of Commerce. (2011). Training Saskatchewan's Doctors. Retrieved from

http://www.saskchamber.com/files/File/Research/2011/Issue\%20in\%20Focus/Training SKDoctor_Dec2011.pdf 
Scheffler, R. M., Liu, J. X., Kinfu, Y., \& Dal Poz, M. R. (2008). Forecasting the global shortage of physicians: an economic-and needs-based approach. Bulletin of the World Health Organization, 86(7), 516-523.

Scott, I. M., Wright, B. J., Brenneis, F. R., \& Gowans, M. C. (2009). Whether or wither some specialties: a survey of Canadian medical student career interest. BMC Medical Education, 9(1), 57.

Smith, J., \& Hays, R. (2004). Is rural medicine a separate discipline?. Australian Journal of Rural Health, 12(2), 67-72.

Statistics Canada. (2011). Canada's rural population since 1851: Population and dwelling counts, 2011 Census. (Catalogue No. 98-310-X2011003). Retrieved from http://www12.statcan.gc.ca/census-recensement/2011/as-sa/98-310-x/98-310x2011003_2-eng.pdf.

Szafran, O., Crutcher, R. A., Banner, S. R., \& Watanabe, M. (2005). Canadian and immigrant international medical graduates. Canadian Family Physician, 51(9), 1242-1243.

Trading Economics. (2012). Rural population in Australia. Retrieved from http://www.tradingeconomics.com/australia/rural-population-wb-data.html.

Trading Economics. (2012). Rural population in the United States. Retrieved from http://www.tradingeconomics.com/united-states/rural-population-wb-data.html.

Viscomi, M., Larkins, S., \& Gupta, T. S. (2012). Recruitment and retention of general practitioners in rural Canada and Australia: a review of the literature. Canadian Journal of Rural Medicine, 18(1), 13-23.

Walton-Roberts, M. (2012). Regional immigration and dispersal: Lessons from small-and medium-sized urban centres in British Columbia. Three Cities and Immigrant Integration: The Future of Second-and Third-Tier Centres. 1(1,920,773), 158-161.

Walton-Roberts, M. W. (2011). Immigration, the university and the welcoming second tier city. Journal of International Migration and Integration, 12(4), 453-473.

Wenghofer, E. F., Timony, P. E., Pong, P. W., \& Pong, R. W. (2011). A closer look at Ontario's northern and southern rural physician demographics. Rural and Remote Health, 11(1591).

Wilkinson, D., Laven, G., Pratt, N., \& Beilby, J. (2003). Impact of undergraduate and postgraduate rural training, and medical school entry criteria on rural practice among Australian general practitioners: national study of 2414 doctors. Medical Education, 37(9), 809-814.

Wilson, P. (2011). Somebody call a doctor. Ottawa: Centre for the North. Retrieved from http://www.centreforthenorth.ca/blogs/herethenorth/somebodycalladoctor. 
Woloschuk, W., \& Tarrant, M. (2002). Does a rural educational experience influence students' likelihood of rural practice? Impact of student background and gender. Medical Education, 36(3), 241-247.

Wong, A., \& Lohfeld, L. (2008). Recertifying as a doctor in Canada: international medical graduates and the journey from entry to adaptation. Medical Education, 42(1), 53-60.

Young, A., Chaudhry, H. J., Rhyne, J., \& Dugan, M. (2012). A census of actively licensed physicians in the United States, 2012. Journal of Medical Regulation, 96(4), 10-20. 
